\title{
A paradigm shift in stormflow predictions for active tectonic regions with large-magnitude storms: generalisation of catchment observations by hydraulic sensitivity analysis and insight into soil-layer evolution
}

\author{
Makoto Tani \\ Laboratory of Forest Hydrology, Graduate School of Agriculture, Kyoto University, Kitashirakawa, Sakyo, \\ Kyoto, 606-8502, Japan \\ Correspondence to: Makoto Tani (tani@kais.kyoto-u.ac.jp)
}

Received: 19 May 2013 - Published in Hydrol. Earth Syst. Sci. Discuss.: 3 June 2013

Revised: 4 October 2013 - Accepted: 10 October 2013 - Published: 12 November 2013

\begin{abstract}
In active tectonic regions with large-magnitude storms, it is still difficult to predict stormflow responses by distributed runoff models from the catchment properties without a parameter calibration using observational data. This paper represents an attempt to address the problem. A review of observational studies showed that the stormflow generation mechanism was heterogeneous and complex, but stormflow responses there were simply simulated by a single tank with a drainage hole when the stormflowcontribution area was spatially invariable due to the sufficient amount of rainfall supply. These results suggested such a quick inflow/outflow waveform transmission was derived from the creation of a hydraulic continuum under a quasisteady state. General conditions necessary for the continuum creation were theoretically examined by a sensitivity analysis for a sloping soil layer. A new similarity framework using the Richards equation was developed for specifying the sensitivities of waveform transmission to topographic and soil properties. The sensitivity analysis showed that saturationexcess overland flow was generally produced from a soil layer without any macropore effect, whereas the transmission was derived mainly from the vertical unsaturated flow instead of the downslope flow in a soil layer with a large drainage capacity originated from the macropore effect. Both were possible for the quick transmission, but a discussion on the soil-layer evolution process suggested that an inhibition of the overland flow due to a large drainage capacity played a key role, because a confinement of the water flow within the soil layer might be needed for the evolution against strong
\end{abstract}

erosional forces in the geographical regions. The long history of its evolution may mediate a relationship between simple stormflow responses and complex catchment properties. As a result, an insight into this evolution process and an inductive evaluation of the dependences on catchment properties by comparative hydrology are highly encouraged to predict stormflow responses by distributed runoff models.

\section{Introduction}

The prediction of runoff response to rainfall is a basic hydrological aim. Since the successful applications of the tank model to many rivers (Sugawara and Katsuyama, 1957; Sugawara, 1995), numerous models have been developed for this purpose. However, it is still difficult to estimate hydrographs in response to hyetographs without a parameter calibration using previous observational data (Sivapalan et al., 2003). There are many reasons for this, but the most essential one is the difficulty in detecting the main properties of a catchment that control its runoff responses (Betson and Ardis, 1978). Most physically based distributed runoff models assume that the surface topography is the controlling factor (e.g. Beven and Kirkby, 1979; O'Loughlin, 1986). However, some hillslope observations, especially in active tectonic regions, do not indicate the dominant effects of topography. This incompatible observational result is attributable to the dominant function of underground pathways, including 
weathered bedrock (Montgomery and Dietrich, 2002; Kosugi et al., 2006; Katsuyama et al., 2010; Gabrielli et al., 2012). Kosugi et al. (2011) demonstrated that a localised bedrock aquifer distribution not following the catchment topography produced a unique triple-peak hydrograph response in a headwater catchment. Most sensitive catchment properties are also embedded underground, outside the obvious surface topography. Difficulties in the prediction of ungauged basins (PUB) (Sivapalan et al., 2003) often stem from the problem of not considering underground structures.

This problem is serious even if a study focuses on only stormflow responses. The stormflow hydrograph is generally distinguished from the entire stream flow by a steep recession gradient. This may be understood simply from the contribution of overland flow to stormflow, and it is quite natural for the stormflow responses to be influenced by surface topography. Early studies of runoff processes considered stormflow to be infiltration-excess overland flow (Horton, 1933). This idea triggered the development of simple kinematicwave routine models (Iwagaki, 1955; Sueishi, 1955). The role of subsurface flow was also noted because of the high infiltration capacity of forest soils (Hewlett and Hibbert, 1968), but saturation-excess overland flow came to be considered as a source of stormflow responses (Dunne and Black, 1970; Freeze, 1972). Because of the low velocity of subsurface flow, such quick stormflow responses could not be explained by it but were considered to result from the high-speed water movement of overland flow in the 1960s. Many of the distributed runoff models used today are based on this concept of saturation-excess overland flow (Ishihara and Takasao, 1964; Beven and Kirkby, 1979). By tracer investigations (Pinder and Jones, 1969; Sklash and Farvolden, 1979), however, the important contribution of pre-event soil water to stormflow was detected, and many well-designed observations were conducted to explain the production of stormflow by soil water movement (Mosley et al., 1979; Pearce et al., 1986; McDonnell, 1990). We now understand that both quick preferential flow and slow water movement within the soil matrix play important roles in stormflow generation processes (Anderson et al., 1997; Tani, 1997), as is also reviewed in Sect. 2 of this paper.

Most of the observational studies mentioned above focused on active tectonic regions with large-magnitude storms and extensive forest cover, such as Japan, New Zealand, and the US Pacific coast, and showed that water movement within a soil layer can contribute to the stormflow response of hillslopes. Furthermore, Dunne's (1983) classification of the generation of stormflow noted the dominant contribution of subsurface flow in humid and topographically steep regions with a thick soil layer. In such regions, overland flow also plays a role in the generation of stormflow (Miyata et al., 2009), depending on the conditions at each site, and further studies quantifying this source of water are required (Gomi et al., 2010). Overall, for prediction of stormflow responses, it may be important to evaluate the dependences of stormflow responses on topographic and soil properties through the mechanism of soil water movement.

This study was motivated by the question of why stormflow responses were not simply predicted by distributed runoff models from the catchment properties (Montgomery and Dietrich, 2002; McDonnell et al., 2007). As noted previously, this may be a result of underground water movement, but how this movement controls stormflow has not been evaluated. General understanding of the relationship between stormflow responses and their generation mechanisms has not been sufficiently obtained, even if the geographical conditions are limited in active tectonic regions and the study target is focused on large-magnitude storms. Although water movement must follow the hydraulics, large spatial heterogeneities beneath the ground may impede the integration of observational and theoretical findings (McDonnell, 2003). Consider how to represent the spatial distribution of soil depth for example. A detailed field investigation for the distribution using a hand auger (Tromp-van Meerveld and McDonnell, 2006), a cone penetrometer (Kosugi et al., 2006), or a combined penetrometer-moisture probe (Yamakawa et al., 2010) were able to provide information about the underground hydrological structure. However, we have to say it has not been successful in providing a core concept necessary for parameterising catchment properties in distributed runoff models. It is believed that this failure resulted from the lack of a basic methodology for generalising the detailed observational findings in the hydraulic framework. The motivation above is extended to how to develop a basic methodology for bridging a serious gap between the observation and model in runoff responses (Weiler and McDonnell, 2007).

This paper is a trial for this gap filling. First of all, key characteristics of stormflow responses and their generation mechanisms will be extracted through a review of the observational studies for storms with large magnitudes. Since such studies may not be free from the individual nature of each site, however, the general principle is then examined by theoretically evaluating the sensitivities of underground water movement to topographic and soil properties. In response to the observational and sensitivity analysis results, we will discuss why specific characteristics of stormflow responses and their generation mechanisms are widely produced under the geographical conditions. The soil evolution process will be presented as a simple answer to the above question. The need for a paradigm shift in the prediction of stormflow responses by distributed runoff models will be concluded by the three components of this paper, i.e. a review of observations, a sensitivity analysis, and a discussion on geophysical influences. 


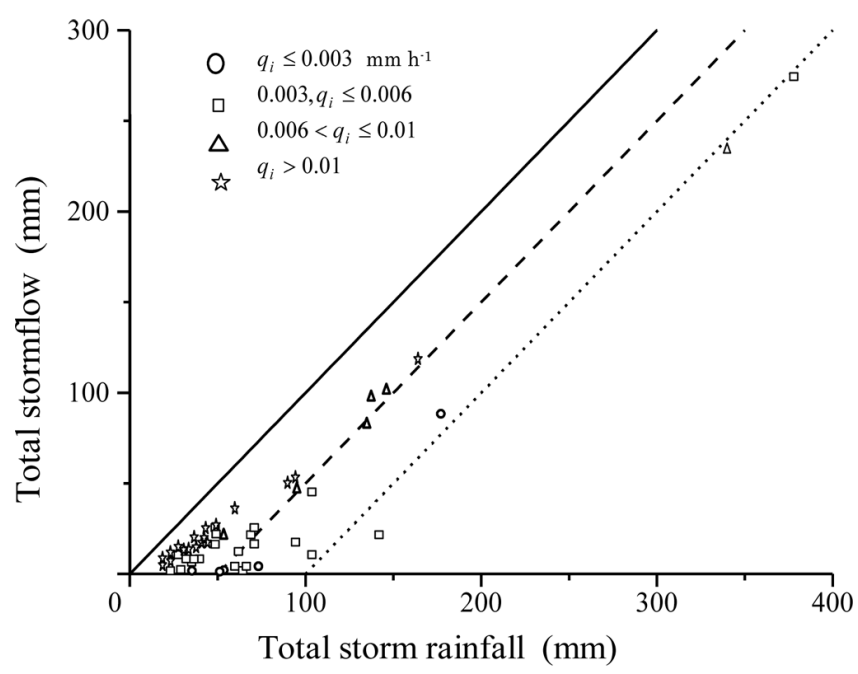

Fig. 1. Relationship of the total stormflow to the total storm rainfall in KT in TEF. $q_{i}$ : runoff rate before the storm event. Solid, broken, and dotted lines indicate $Q=R, Q=R-50, Q=R-100$, respectively, where $R$ is the total storm rainfall and $Q$ is the total stormflow. After Tani and Abe (1987).

\section{Hydraulic continuum from a review on site observations}

\subsection{Extension of the stormflow contribution area}

Runoff discharge is generally distinguished into stormflow and baseflow by a recession gradient, and the stormflow responses and their generation mechanisms are largely influenced by the magnitude of a storm. In general, when rainfall begins, stormflow will generate from local wet zones and have very small volume. As rainfall increases, the contribution area of stormflow extends with time (Hewlett and Hibbert, 1968). However, when the cumulative rainfall becomes large enough, the contribution area may extend to almost the entire catchment. This tendency can be detected in the relationship of stormflow volume per unit catchment area to the total rainfall volume of each storm event, which has been illustrated frequently as a means to understand the storm runoff characteristics in a catchment (Soil Conservation Service, 1972; Okamoto, 1978). Figure 1 shows an example of catchment Kitatani (KT) in the Tatsunokuchi-yama Experimental Forest (TEF), Okayama, Japan (Tani and Abe, 1987). When the amount of rainfall is small, stormflow is low because most of the rainwater is stored in the soil layer by various types of storage, such as canopy storage, litter storage, and absorption within small pores with low matric potential. The plots in Fig. 1 show clear control by the initial runoff rate as well as cumulative rainfall, suggesting the important effect of dryness before a storm event. The volume of stormflow increases more quickly with rainfall when cumulative rainfall exceeds a threshold value.
After the cumulative rainfall exceeds the threshold volume in a large-scale storm, almost all of the additional rainwater tends to be allocated to stormflow (Tani, 1997). Therefore, we can imagine that the entire catchment area eventually contributes to stormflow production, even though some rainwater may still be allocated to deep infiltration in catchments with geologies such as granite (Shimizu, 1980). However, the most important characteristic after the cumulative rainfall becomes large enough during a large-magnitude storm is that the contribution area is spatially invariable. Although such large storms may be infrequent, they can provide very important information about stormflow responses and their mechanisms. Two examples from hillslope observational studies are reviewed below.

\subsection{Stormflow observations in catchments with fixed contribution areas}

A valuable study of sprinkling experiments was conducted in the Oregon Coast Range, USA, to understand the stormflow mechanism under the ground (Anderson et al., 1997; Montgomery et al., 1997; Ebel et al., 2007). The site labelled CB1 was a steep zero-order catchment $\left(860 \mathrm{~m}^{2}\right.$ and $\left.43^{\circ}\right)$ on Eocene volcaniclastic sandstone bedrock. Rainfall of a relatively weak intensity (average of $1.65 \mathrm{~mm} \mathrm{~h}^{-1}$ ) was supplied for a long duration (7 days), and all the water infiltrated into the soil. Two weirs (upper and lower) measured flow rates from both colluvium and fractured bedrock in the catchment, where the flow through the upper weir was separated from that through the lower weir, which was located $15 \mathrm{~m}$ downstream. As shown in Fig. 2, the flow rates measured at the upper and lower weirs were roughly constant, equal to about one-third of the supplied rainwater intensity, after the sufficient rainfall was supplied. Both flow rates had a daily oscillation due to evapotranspiration and wind-induced variations in the rainfall intensity. The rainfall intensity with a large spatial distribution was manually measured twice daily, and the flow rate at each weir was measured by hand. Thus, temporal changes could not be recorded in detail (Ebel et al., 2007), and the results illustrated in Fig. 2 can be used only for a rough comparison because of the time lags. However, the results indicated that during the 4-day period when the flow was nearly steady, the rainfall of $1.65 \mathrm{~mm} \mathrm{~h}^{-1}$ was allocated to the averaged total flow rate of $1.1 \mathrm{~mm} \mathrm{~h}^{-1}$. Although deep infiltration constituted a leakage of $0.5 \mathrm{~mm} \mathrm{~h}^{-1}$ (Anderson et al., 1997), the remaining rainwater contributed to stormflow responses, and the constant discharge rate suggested the temporal invariability of its contribution area.

Figure 2 clearly shows differences between the two types of loss mentioned above: storage by the canopy and litter and absorption within small pores with low matric potential detected from the small flow rate in the early stage, and the infiltration into the deep layer which was estimated as a leakage of $0.5 \mathrm{~mm} \mathrm{~h}^{-1}$ that remained even during the later stage in a nearly steady state. The flow rate through each of the 


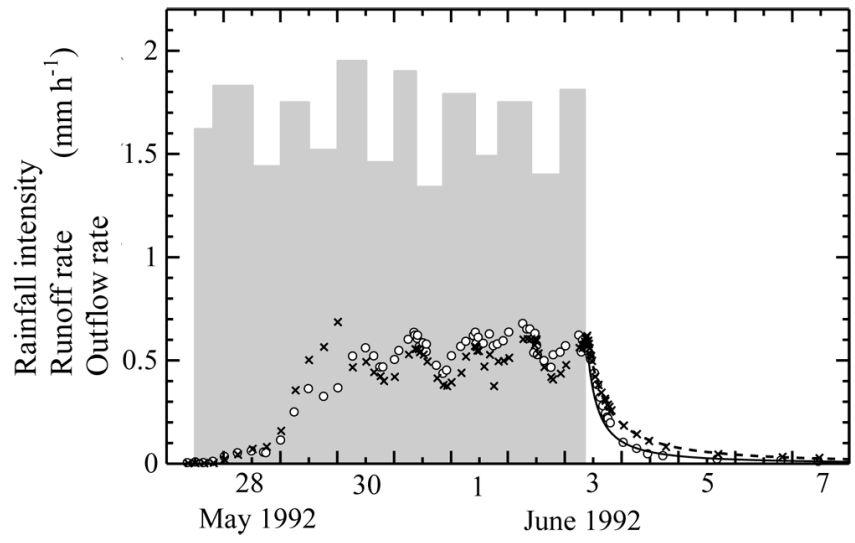

Fig. 2. Sprinkled rainfall and runoff responses in CB1. Bar: rainfall; $\bigcirc$ : runoff rate at the upper weir; $x$ : runoff rate at the lower weir. The solid and broken lines are the outflow rates calculated by TANK using the functional relationship between storage and the outflow rate in Eq. (2) with a $p$ value of 0.3 and $k$ values of 11 for the upper weir and 20 for the lower weir. Recreated from Fig. 3 of Anderson et al. (1997); courtesy of Dr. Suzanne Anderson.

weirs roughly followed, with a small delay, the daily oscillation of rainfall intensity during the nearly steady state, regardless of the limitations of the hand measurements. For the flow response to rainfall, Anderson et al. (1997) found the following processes through two kinds of tracer experiments. A high-speed subsurface flow from the fractured bedrock to the outlet through the colluvium was detected by bromide point injections into the saturated materials. Another experiment using sprinkler water labelled by deuterium showed plug flow without preferential flow for the vertical unsaturated water movement.

These tracer experiments strongly suggested that a combination of a vertical plug flow in the unsaturated zone and high-speed downslope flow in the saturated zone can produce rapid flow responses at the timescale of stormflow to daily rainfall oscillations. Note that although water must theoretically move according to the gradient of hydraulic head, the unsaturated vertical flow and saturated downslope flow were seemingly disconnected by remaining a dry portion of the soil layer in the early stage of the experiment. This disconnection was hydraulically resulted from a negligible small value of the unsaturated hydraulic conductivity in the dry portion compared to that in each of the wet zones near the surface above the wetting front and at the capillary fringe near the saturated zone. The flows were efficiently connected during the nearly steady-state stage after the entire soil layer had become sufficiently wet. Thus, we now defined this substantively connected system as "hydraulic continuum" (called $\mathrm{HC}$ in this paper). This experiment showed that a creation of $\mathrm{HC}$ connecting the unsaturated and saturated flows played an important role in quick flow responses. Approximations that neglect unsaturated flow have often been used for analysing water movement beneath the ground (Brutsaert, 2005), but the results from CB1 suggest that such an approximation should be rejected here because it is not fixed whether the saturated or the unsaturated flow has the larger effect on stormflow responses. The important role of hydrologic or hydraulic connectivity in catchment processes has already been discussed elsewhere (Michaelides and Chappell, 2009; Oldham et al., 2013), and HC, efficiently connecting the unsaturated and saturated flows, will be used as a key concept for the flow responses in this paper.

A similar runoff process was estimated from two small forested catchments, KT (17.3 ha) and MN (Minamitani of 22.6 ha, an adjacent catchment of KT), in TEF (Tani, 1997). The soil was a clay loam derived from the sedimentary rock. Although the soil was generally deep, the two catchments were both characterised by high stormflow volumes when most of the rainfall was allocated to the stormflow under wet conditions after the rainfall volume exceeded the threshold of cumulated rainfall, as shown in Fig. 1 for KT. For quick flow responses, the vertical water movement was not estimated as a preferential flow but as unsaturated flow through the soil matrix. Evidence was further derived from measurement of matric potential in the soil layer on a steep planar hillslope $\left(500 \mathrm{~m}^{2}\right.$ and $\left.35^{\circ}\right)$ in $\mathrm{MN}$. In the early stage of the storm, the dry portion within the soil, substantively disconnecting the water flow, gradually disappeared due to the downward development of a wetting front. Stormflow generation was enhanced after HC was created by the water-flow connection in the entire hillslope. The matric potential near the soil surface had a clear positive relationship with the given rainfall intensity, as predicted theoretically from Darcy's law by Rubin and Steinhardt (1963), demonstrating the vertical water movement by the unsaturated flow through the soil matrix instead of the preferential flow (Tani, 1997).

In addition to this planar hillslope observation, another study in TEF showed that the groundwater level at $15 \mathrm{~m}$ depth in a steep zero-order catchment with very thick soil increased quickly in response to rainfall, similar to the stormflow rate during wet conditions in an upper soil layer, although the level did not respond during dry soil conditions (Hosoda, 2008). Quick downslope water movement was not explicitly traced, as it was in CB1, but a quick stormflow response with volume comparable to that of rainfall frequently occurred without overland flow in these catchments. This result suggested that these stormflow characteristics may be produced from $\mathrm{HC}$ similar to that in the $\mathrm{CB} 1$ catchment. Next we investigate the nature of $\mathrm{HC}$ using the model of a single tank with a drainage hole.

\subsection{Characteristics of inflow/outflow transmission by a single tank with a drainage hole}

A model of a single tank with a drainage hole at its bottom (called TANK in this paper) is a typical component of many storage-type runoff models, such as the Sugawara's (1995) tank model, the HYCYMODEL (Fukushima and Suzuki, 


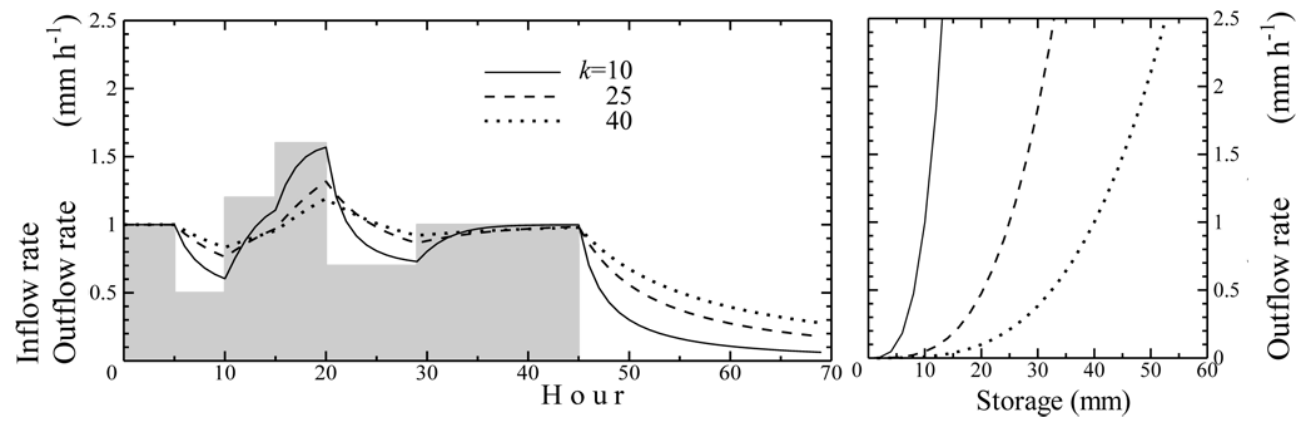

Fig. 3. Schematic example of outflow rates calculated by TANK in response to fluctuations in the inflow rate around the average of $1 \mathrm{~mm} \mathrm{~h}^{-1}$ and their recession limbs after the inflow stops (left panel). The functional relationships between storage and the outflow rate used in the calculations in the left panel are displayed in the right panel. The common $p$ value of 0.3 and the three $k$ values described in the left panel were used for the TANK calculations.

1988), and the TOPMODEL (Beven and Kirkby, 1979). Although these models contain an algorithm for rainwater allocation to stormflow and loss - the so-called separation process of effective rainfall - stormflow responses may have a common characteristic represented by TANK. A general function for inflow/outflow waveform transmission by TANK can be written as

$$
\frac{\mathrm{d} V_{\mathrm{T}}}{\mathrm{d} t}=i-o,
$$

where $V_{\mathrm{T}}$ is the TANK storage, $i$ is the given inflow rate such as effective rainfall intensity, and $o$ is the outflow rate such as the stormflow rate (all per unit catchment area). Most runoff models have represented the relationship between $o$ and $V$ for the stormflow components (Kimura, 1961; Kadoya and Fukushima, 1976) as

$V_{\mathrm{T}}=k o^{p}$,

where $k$ and $p$ are parameters. The inflow/outflow waveform transmission by TANK typically exhibits a "quasi-steady state" characteristic (called QSS in this paper). A QSS system is characterised by a dynamic equilibrium of storage such that the outflow fluctuates in response to a small change in inflow around an average rate. After the inflow in this system stops, outflow gradually decreases, but the same functional relationship between storage and the outflow rate as exists during dynamic equilibrium is kept in this recession stage (Meadows, 2008). This characteristic of a QSS system is derived strictly from the one-to-one relationship between storage and flow rate without hysteresis. Note that runoff responses consisting of components with different timescales do not present the behaviour of a QSS as suggested from Sugawara's tank model consisting of serially concatenated tanks. Therefore, catchment runoff responses are never characterised by QSS, but we can say that stormflow responses tend to represent this characteristic after the separation of effective rainfall.
The quantitative properties of the QSS system are examined further here. The water balance of Eq. (1) is transformed to

$\frac{\mathrm{d} o}{\mathrm{~d} t}=\frac{i-o}{\mathrm{~d} V_{\mathrm{T}} / \mathrm{d} o}$.

This equation implies that when $i=o, o$ is constant; when $i>o, o$ increases; and when $i<o, o$ decreases. In addition, $\mathrm{d} o / \mathrm{d} t$ is controlled by $\mathrm{d} V_{\mathrm{T}} / \mathrm{d} o$. Therefore, if the system is in a quasi-steady state, the increase/decrease rate of the outflow is simply controlled by the differential coefficient of storage with respect to outflow rate in a steady state.

The left panel in Fig. 3 is a schematic example showing the response of the outflow rate to a fluctuation in the inflow rate, the average of which is $1 \mathrm{~mm} \mathrm{~h}^{-1}$. The relationships between storage and outflow rate are represented by Eq. (2) and illustrated in the right panel of Fig. 3. We used a common $p$ value of 0.3 and three different $k$ values of 10, 25, and 40 in Eq. (2) in consideration of the range of observed recession flows, as explained later in Sect. 2.4. The figure clearly shows the dependence of the increase/decrease rate of outflow on $\mathrm{d} V_{\mathrm{T}} / \mathrm{d} o$, not only during the dynamic equilibrium in response to the cyclic fluctuations of inflow but also in the recession stage after its stop.

\subsection{Application of TANK to observations}

For catchments KT and MN in TEF, almost all of the rainfall was allocated to stormflow under wet conditions, as described in Sect. 2.1 by Fig. 1. For this case, we do not need an algorithm of the effective-rainfall separation process because the stormflow contribution area is fixed in the entire catchment. Figure 4 shows the simulated stormflow responses in the KT and MN catchments to a typhoon storm in September 1976, with a total rainfall of $375 \mathrm{~mm}$. Ten-minute rainfall and runoff data were used here, and the rainfall was directly inputted to TANK. The baseflow rate before the storm event was very small $\left(0.0053 \mathrm{~mm} \mathrm{~h}^{-1}\right.$ for KT and $0.0067 \mathrm{~mm} \mathrm{~h}^{-1}$ 


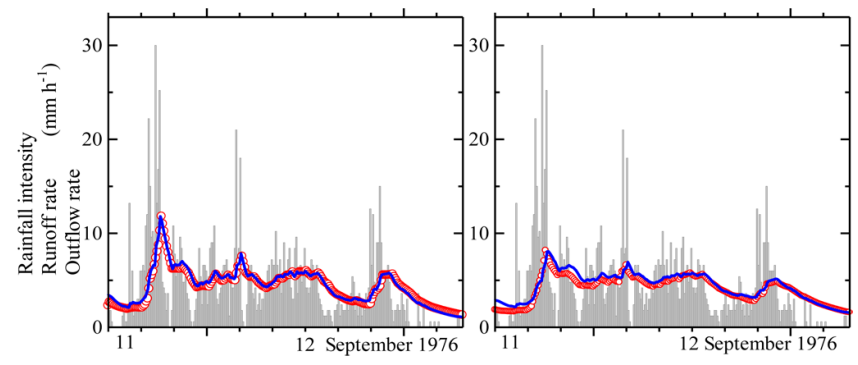

Fig. 4. Storm hydrographs, observed and simulated by TANK, in response to a typhoon in September 1976 at KT (left) and MN (right) in TEF. Bar: $10 \mathrm{~min}$ rainfall intensity (displayed in $\mathrm{mm} \mathrm{h}^{-1}$ ). Red circle: observed runoff rate. Blue line: simulated outflow rate. The lines were calculated by TANK using the functional relationship between storage and the outflow rate given by Eq. (2) with a common $p$ value of 0.3 and $k$ values of 25 for KT and 40 for MN.

for MN); thus we neglected the effect of the baseflow increase on the hydrograph during the event. Figure 4 plots the later stage of the entire event after the stormflow contribution area might have extended to the entire catchments. The optimised value of $p$ for both catchments was 0.3 , and the values of $k$ for KT and MN were 25 and 40, respectively. Extremely close agreement was obtained for each of the catchments, and the lower peaks and gentler recession limbs for $\mathrm{MN}$ vs. KT were accurately simulated by the difference in $k$ between them. This probably reflects thicker soil layers with gentler slopes in $\mathrm{MN}$ than KT, considering that there was a slightly larger annual evapotranspiration for MN than KT, as estimated from the $69 \mathrm{yr}$ annual water balance there (Tani and Hosoda, 2012).

For CB1, the latter half of the sprinkler experiment was nearly in a steady state with a fixed contribution area, but the total of the flow rates fluctuated around $1.1 \mathrm{~mm} \mathrm{~h}^{-1}$, less than the rainfall rate because the constant loss rate remained continuously. It was difficult to evaluate the simulation results by TANK in terms of runoff responses during the nearly steady state due to the manual measurements of rainfall intensity and runoff rates. The recession stage of runoff rate can be simulated only for each of the upper and lower weirs (Fig. 2). An optimised value of $p$ of 0.3 was also used here, and the optimised values of $k$ were 11 and 20 for the upper and lower weirs, respectively. The values of $k$ were slightly lower than those of TEF, but as compared with the calculations represented in Fig. 3, the hydrographs for these catchments commonly have quick recession limbs with a small range of half-lives (roughly from several hours to one day) despite the large differences in catchment properties between them.

\subsection{Stormflow responses for general cases}

The accurate simulation results for TEF and CB1 shown above suggest that stormflow responses can be represented by TANK, described by the storage and flow-rate relationship in Eq. (2), even though two flow mechanisms with different speeds were involved. A common characteristic of these examples is that the stormflow contribution area was extended to the entire catchment and invariable after a sufficient amount of rainfall supply. This spatial invariability is important for a QSS system. Usual catchment runoff responses do not show this characteristic, as was mentioned in Sect. 2.3, and the plural contribution areas for stormflow and baseflow are both variable. Nonetheless, such good simulation results using Eq. (2) have been widely found in practical stormflow analyses for flood management purposes in mountainous catchments in Japan when separation of effective rainfall was conducted before hydrograph optimisation (Kimura, 1961; Sugiyama et al., 1997). Another example is an application of HYCYMODEL to seven small mountainous catchments (Tani et al., 2012). This model included TANK as part of the stormflow response. The application demonstrated that the gradients of stormflow recessions in catchments with different land-use histories were similar, except for a catchment covered with bare land, where overland flow produced very quick recessions. A small range of stormflow recession gradients was also obtained from a comparison among about 90 mountainous catchments in Japan (Okamoto, 1978).

These TANK application results may suggest that, after the separation of effective rainfall, the stormflow contribution area can be assumed approximately invariable for a short time during the storm event. Regardless of such empirically good applications, it is not clear why the stormflow responses can be simulated well by TANK with the parameter values of $p$ and $k$ shown in Eq. (2). The $p$ value of 0.6, reflecting the Manning equation for overland flow, was often recommended (Kadoya and Fukushima, 1976; Fukushima and Suzuki, 1988), but this idea may be rejected because both saturated and unsaturated flows within the soil layer may involve the storage and flow-rate relationship instead of simple overland flow. Furthermore, it is also difficult to discern a physical meaning for the $p$ value of 0.3 optimised for both CB1 and TEF. Strictly speaking, the exponential relationship in Eq. (2) is itself empirical and is difficult to explain on a physical basis.

Accordingly, although HC under QSS represented by TANK may certainly provide an essential insight into the relationship between stormflow responses and their generation mechanisms, the physical background has not yet been determined for this concept. In Sects. 3 and 4, we attempt to hydraulically evaluate the sensitivity of flow responses to topographic and soil properties of a soil layer on a hillslope. Despite the simple assumptions involved in the sensitivity analysis, we obtain key hydraulic conditions required for understanding stormflow responses in active tectonic regions with large-magnitude storms. 


\section{Method of sensitivity analysis}

\subsection{Connection of observation and theory through the concept of hydraulic continuum}

Although the flow mechanism in CB1 was found to be a combination of unsaturated flow within the soil matrix and quick saturated downslope flow, this conclusion was derived from only an individual result of tracer experiments. The observation result in TEF suggested a similar mechanism but lacked tracer evidence. Overland flow was not a major source of stormflow in either observation, but a contribution from it cannot be rejected in general (Miyata et al., 2009; Gomi et al., 2010). Thus, we have to assume that such observations are site-specific and that an explanation for stormflow generation by a different mechanism may be possible. Generalisation of the mechanism determined from site observations may require theoretical consideration. This section quantifies the relationship between simple stormflow responses and their complex mechanisms based on hydraulic theory. For this purpose, sensitivities of these responses to topographic and soil properties are investigated, considering the heterogeneity involved in the mechanisms. We use a methodology proposed by Tani (2008) for our sensitivity analysis because it was developed to theoretically connect flow responses from $\mathrm{HC}$ with water movement mechanisms in a sloping permeable domain.

In Tani's (2008) method, the runoff buffering potential (RBP) is defined as the difference between the water storage volumes within a domain in response to two steady-state outflow rates. Hence,

$\mathrm{RBP} \equiv \int_{f_{\mathrm{a}}}^{f_{\mathrm{b}}} \frac{\mathrm{d} V}{\mathrm{~d} f} \mathrm{~d} f=V\left(f_{\mathrm{a}}\right)-V\left(f_{\mathrm{b}}\right)$,

where $f$ is the outflow rate per unit horizontal slope length, and $V$ is the water storage volume within a permeable domain. The meaning of RBP can be understood easily by comparing the right and left panels in Fig. 3. As shown in that figure, the curve with a larger increase in storage in response to a given outflow-rate increase in the right panel produced a gentler fluctuation of the outflow rate in the left panel. Therefore, a larger RBP is an index for a gentler outflow-rate fluctuation. A larger RBP also contributes to a larger decrease in the peak outflow rate in usual non-steady natural conditions because of its smoothing effect, which is the reason for the name "runoff buffering potential". When both $f_{\mathrm{b}}$ and $f_{\mathrm{a}}$ are brought close to $f_{\mathrm{m}}$ without limit, this integral form in Eq. (4) is converted to a differential form:

$\left.\left.\operatorname{RBPI}\right|_{f_{\mathrm{m}}} \equiv \frac{\mathrm{d} V}{\mathrm{~d} f}\right|_{f_{\mathrm{m}}}$,

where RBPI is the index of RBP (newly introduced here and called RBPI) and $f_{\mathrm{m}}$ is the averaged outflow rate around which $f$ fluctuates. Figure 3 also shows that both the given inflow rate and the calculated outflow rate in the left panel fluctuate around $f_{\mathrm{m}}=1 \mathrm{~mm} \mathrm{~h}^{-1}$, and each of the outflowrate fluctuations shows its own delay in response to the RBPI value represented as the gradient of the curve (i.e. $\mathrm{d} V / \mathrm{d} f$ in the right panel).

For the recession stage from a storm event, substituting Eq. (5) into Eq. (3) gives the recession gradient at $f$ as

$\frac{\mathrm{d} f}{\mathrm{~d} t}=\frac{-f}{\mathrm{~d} V / \mathrm{d} f}=\frac{-f}{\mathrm{RBPI}}$.

Hence the half-life $\left(T_{\mathrm{h}}\right)$ at $f$ is described as

$T_{\mathrm{h}}=-\ln (0.5) \mathrm{d} V / \mathrm{d} f=-\ln (0.5) \mathrm{RBPI}$.

This shows that the recession outflow rate from $\mathrm{HC}$ characterised by a QSS system is accurately reduced to a simple integral of the differential equation in Eq. (6). The left panel of Fig. 3 also shows an example of the recession in response to each of the RBPI values.

The purpose of this section on a sensitivity analysis is to connect simple stormflow responses and complex flow mechanisms as already mentioned. We have to pay particular attention to a classic problem on hydrology that a good agreement of simulated and observed hydrographs cannot identify the conditions assumed in the used runoff model (Betson and Ardis Jr., 1978). From this point of view, the creation of HC under QSS commonly characterised by both flow processes in a catchment with strong heterogeneities and a simply idealised domain can contribute to our purpose. As noted in Sect. 2, the observational studies demonstrated that HC was created even in catchments with heterogeneous underground flow mechanisms consisting of slow unsaturated flow and quick downslope flow. Equation (5) for the RBPI and Eq. (6) for the outflow recession were strictly valid for HC created in every permeable domain based on the hydraulics. Accordingly, we can focus on determining what hydraulic conditions are required for producing the common character - that is, a quick inflow/outflow waveform transmission from HC under QSS - instead of optimising the model parameters for an individual hydrograph agreement. The conditions obtained from this theoretical sensitivity analysis may be more generally approved to many complex catchments.

\subsection{Sensitivity analysis for a sloping soil layer using a similarity framework}

A sloping soil layer with constant topography and homogeneous hydraulic properties was considered for our sensitivity analysis, which used a two-dimensional form of the Richards equation consisting of Darcy's law and the continuity equation. The layer analysed follows that of Tani (2008), and a schematic is shown in Fig. 5. We also additionally included a handling methodology for the topographic and soil properties and a strategy for the similarity framework, which plays a 


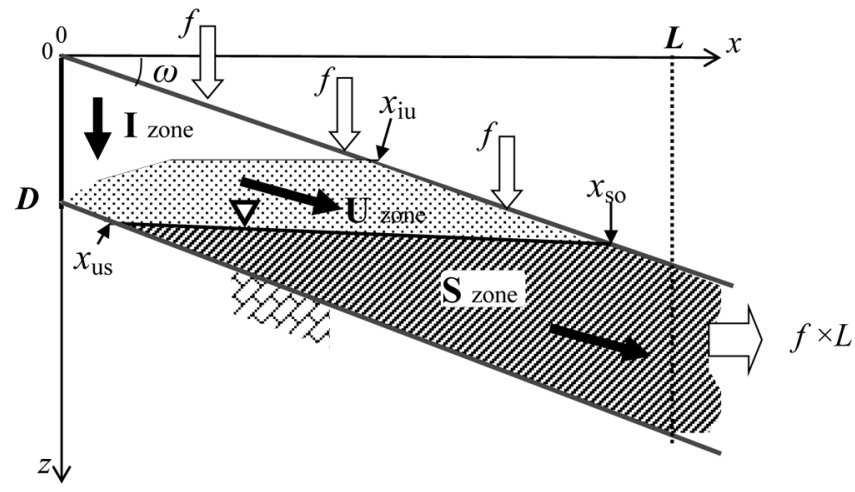

Fig. 5. Schematic of a sloping permeable domain with approximate categorisation of the pressure head (I, U, and S zones). The horizontal distances involving the categorisation of $x_{\mathrm{iu}}, x_{\mathrm{us}}$, and $x_{\mathrm{so}}$ are also plotted.

key role in our sensitivity analysis specifying, with high generality, the critical hydraulic conditions. However, so as not to disrupt the logical flow of this section, these are described in the appendices of this paper. The fundamental equations are introduced in Appendix A, and the main body of the text presents the key points of the sensitivity analysis.

Assume a steady state for the soil layer in response to rainfall supply with a constant intensity, the range of which is less than the saturated hydraulic conductivity $K_{\mathrm{S}}$. The spatial distribution of pressure head within a soil layer can be calculated by the Richards equation (Eq. A1). Consider a soil layer under a steady state in response to a constant intensity of the rainfall first. When the rainfall is changed to a different constant intensity, this change in the surface boundary condition may be transmitted to the spatial distribution of pressure head in the whole soil layer governed by the local hydraulic head gradient according to the Richards equation, and the outflow rate from the layer may be shifted to a new steady-state rate. Because the total volumetric water content integrated over the soil layer has a one-to-one relationship with the outflow rate for both the new and old steady states, this layer will behave as HC under QSS, similar to TANK, whose flow responses are illustrated in the left panel of Fig. 3. Therefore, from the relationship of the total water storage $V$ to the steady outflow rate per unit slope length $f_{\mathrm{m}}$, which is equal to the rainfall intensity because of the steady state, we can calculate the RBPI (Eq. 5) and the recession hydrograph (Eq. 6) for this soil layer. Thus, the sensitivity of the RBPI and recession characteristic to topographic and soil properties can be assessed through this calculation process. The macropore effect on water movement was considered in only the saturated zone as a hydraulic conductivity that is $\varepsilon$ times larger than $K_{\mathrm{S}}$ according to a parameterisation proposed by Tani (2008) (Eqs. A14 and A15); this effect may not be present in an unsaturated zone due to a negative potential (Wang and Narashimhan, 1985; Nieber and Sidle, 2010).
Tani (2008) categorised the spatial distribution of the pressure-head value in a steady state within a soil layer on a steep slope, which is important for understanding the water flow in the layer described by the Richards equation. Three zones were approximately categorised (as shown in Fig. 5): the I zone with vertical unsaturated flow, the U zone with unsaturated downslope flow, and the $\mathrm{S}$ zone with saturated downslope flow. Regardless of the complex appearance of saturated-unsaturated flow, the pressure-head distribution was characterised simply by this hydraulic zoning. It is therefore useful to understand the dependence of RBPI on slope properties. Tani (2008) also formulated indicators partitioning the three zones. The indicators modified into dimensionless form for our similarity framework are described within Appendix B. It is important for generalisation that the categorisation can provide a hydraulic background for both the vertical unsaturated flow and downslope saturated flow suggested from the on-site observations in CB1 and TEF because these two components may respectively reflect the I zone and the $\mathrm{S}$ zone with the $\mathrm{U}$ zone lying above.

To make our sensitivity analysis more general, a similarity framework was introduced using a small number of dimensionless parameters (Eqs. B1 to B9). A steady-state outflow rate per unit slope length, $f_{\mathrm{m}}$, equal to the rainfall intensity, was selected as a criterion for the nondimensionalisation. The similarity frameworks for the pressure-head distribution and RBPI are described in Appendices B and $\mathrm{C}$, respectively. Six parameters were introduced. Three are soil physical properties: $\kappa$, the ratio of saturated hydraulic conductivity $K_{\mathrm{s}}$ to $f_{\mathrm{m}} ; \sigma$, the standard deviation of the $\log$ transformed soil pore radius; and $\varepsilon$, the parameterisation of the macropore effect in $K_{\mathrm{s}}$. Two are topographical: $\omega$, the slope angle, and $\lambda$, the ratio of the horizontal soil-layer length $L$ to the representative length scale $l$ (Eq. B2). The remaining parameter, $\delta$, is the ratio of soil depth $D$ to $l$. Here, the length scale $l$ is derived from the flow rate criterion $f_{\mathrm{m}}$ by utilising the relationship of $K_{\mathrm{S}}$ to the arithmetic mean of the soil pore radius $r_{\mathrm{a}}$ (Kosugi, 1997a) (Eqs. A11 to A13), and is dependent only on $f_{\mathrm{m}}$, as defined in Eq. (B2), free from any properties of the soil layer. The RBPI calculated from the integration of volumetric water content distribution in the soil layer was made dimensionless $\left(\mathrm{RBPI}_{*}\right)$ using the total pore volume included in the soil layer with depth $l$ (Eq. C2). Therefore, when a rate of $f_{\mathrm{m}}$ is assumed, the sensitivity of $\mathrm{RBPI}_{*}$ to one of the six dimensionless parameters representing the topographic and soil properties can be compared with the sensitivity to another without any mutual interferences. This similarity framework can provide a methodology for generally quantifying which topographic and soil properties contribute to a large RBPI when $f_{\mathrm{m}}$ is given as a criterion. Once the value of RBPI is determined, the sensitivity of inflow/outflow waveform transmission around the average rate of $f_{\mathrm{m}}$ can be assessed directly in Eq. (5). Moreover, the sensitivity of outflow recession rate from $f_{\mathrm{m}}$ can be also evaluated through the numerical integral using Eq. (6). In the 
dimensionless form, the calculations for them were respectively made in Eqs. (C3) and (C5).

Although the soil layers in our analysis in this section are based on a very simple assumption, they retain most of the core characteristics of the field observations in CB1 and TEF described in Sect. 2, which showed HC under QSS consisting of vertical unsaturated flow following Darcy's law and downslope saturated flow with quick velocity. Spatial heterogeneities in the hillslope are a major concern with respect to generality, and our parameterisation of the macropore effect by the saturated hydraulic conductivity, represented by $\varepsilon$, may not strictly reflect the pipe-like preferential pathways estimated by the tracer experiment in CB1. However, both of them can be regarded as similar from the hydraulic point of view because large-size pores commonly provide a high drainage capacity for the saturated downslope flow. Considering such a heterogeneity influence, the next section about results of the sensitivity analysis presents the hydraulic conditions generally producing quick inflow/outflow waveform transmission and outflow recession from $\mathrm{HC}$ under QSS created within the sloping soil layer.

\section{Results of sensitivity analysis}

\subsection{Sensitivity for RBPI}

Figure 6 shows the sensitivity of $\mathrm{RBPI}_{*}$ to $\kappa$ and $\lambda$ when $\omega=30^{\circ}, \delta=1$, and $\sigma=1.4$. The left panel is for $\varepsilon=1$ without any macropore effect, and the right panel is for $\varepsilon=100$ with a large effect. The horizontal distances of indicators categorising the pressure-head distribution, such as $x_{\mathrm{iu} *}, x_{\mathrm{us} *}$, and $x_{\mathrm{so} *}$ in Eqs. (B10) to (B14), are plotted along the ordinate axis for the horizontal distance $x_{*}$, also representing the layer length $\lambda$. This categorisation shows which of the I, U, and $\mathrm{S}$ zones compose the vertical profile at any horizontal point $x_{*}$ along the sloping soil layer. For example, there is no $\mathrm{S}$ zone in the vertical profile when $x_{*}<x_{\mathrm{us} *}$ because only the unsaturated flow is sufficiently responsible for a small rate of the downslope flow. The I zone exists when $x_{*}<x_{\mathrm{iu} *}$, and saturation-excess overland flow is generated when $x_{*}>x_{\mathrm{s} 0 *}$.

In the left panel, large $\mathrm{RBPI}_{*}$ values are shown along a stripe between the $x_{\mathrm{us} *}$ and $x_{\mathrm{so} *}$ lines. This means that RBPI* has a maximum value when the groundwater table is rising (the $\mathrm{S}$ zone is growing), but it rapidly decreases towards the upper-left area of the stripe $\left(>x_{\mathrm{SO} *}\right)$ because the saturationexcess overland flow extending upslope causes decreasing $\mathrm{RBPI}_{*}\left(=\mathrm{d} V_{*} / \mathrm{d} f_{*}\right)$. Along the ridge of $\mathrm{RBPI}_{*}$, its value decreases with $\kappa$ because of the effect of the soil physical properties: the volumetric water content in the unsaturated zone of a clayey soil with a small $\kappa\left(=K_{\mathrm{s}} / f_{\mathrm{m}}\right)$ value is close to saturation, and the increase in the total water storage $V$ in response to a groundwater table rise is small, resulting in a small increase in $\mathrm{RBPI}_{*}$ compared to that in a sandy soil with a smaller water content in its unsaturated zone. Note that this

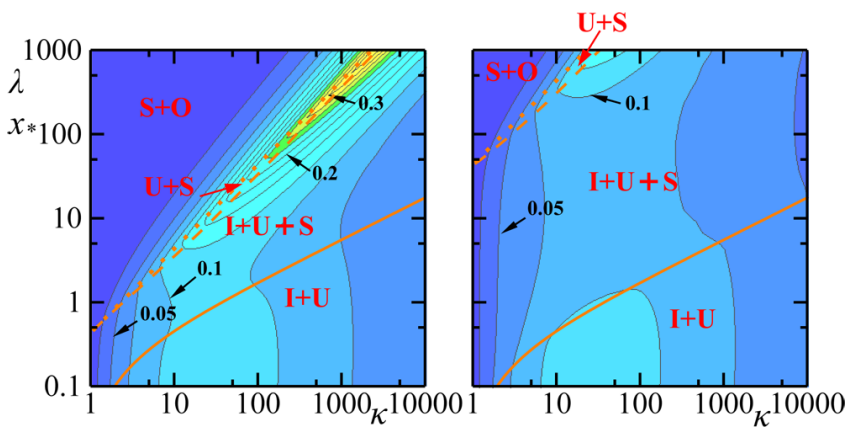

Fig. 6. Contour plots of $\mathrm{RBPI}_{*}$ against $\kappa$ and $\lambda$ for $\varepsilon=1$ (left) and 100 (right). Orange solid, dashed, and dotted lines represent the horizontal distances for the end point of the I zone $\left(x_{\mathrm{iu} *}\right)$, the start point of the $\mathrm{S}$ zone $\left(x_{\mathrm{uS} *}\right)$, and the start point of the saturation-excess overland flow $\left(x_{\mathrm{SO} *}\right)$, respectively. The red letters indicate which zones are included in the vertical profile at each horizontal point of the sloping soil layer (see Fig. 5).

tendency of a small $V$ increase for a clayey soil has been usually represented by a small value of "effective porosity" in an approximation of the groundwater flow with neglecting the unsaturated flow process (Brutsaert, 2005). In the lower area with small $x_{*}$ (i.e. short slope length), $\mathrm{RBPI}_{*}$ is controlled mainly by the vertical unsaturated flow because most of the soil layer is covered with the I zone.

In the right panel with a large macropore effect, $\mathrm{RBPI}_{*}$ is generally lower than it is in the left panel. This occurs because of a smaller storage change derived from the large drainage capacity of the $\mathrm{S}$ zone due to the macropore effect compared to that for the no-macropore effect case in the left panel. Because a large macropore effect causes a quite thin $\mathrm{S}$ zone and the total downslope flow in the $\mathrm{U}$ and $\mathrm{S}$ zones remains close to the bottom of the soil layer, $\mathrm{RBPI}_{*}$ is almost independent of the storage change in the $\mathrm{U}$ and $\mathrm{S}$ zones. Hence, most of the soil layer is covered with the I zone, where water moves vertically, and $\mathrm{RBPI}_{*}$ is sensitive to only the storage change in the I zone as if the slope length were short. Within the I zone, the volumetric water content has the same value throughout the soil layer, which has an unsaturated hydraulic conductivity that is equal to the rainfall intensity; thus the rainwater can be transmitted vertically by the gradient of the gravity force (not by the pressure-head gradient) as was theoretically demonstrated by Rubin and Steinhardt (1963). Therefore, $\mathrm{RBPI}_{*}$ is controlled only by the vertical unsaturated flow in the I zone regardless of the horizontal soil-layer length $\lambda$. The distribution of $\mathrm{RBPI}_{*}$ in the right panel clearly shows this tendency.

\subsection{Sensitivity for recession outflow rate}

Figure 7 compares the recession outflow rate from $f_{*}=1$ at the starting point $t_{*}=0$. To compare the calculation results with the observations in Sect. 2, dimensional variables produced by substituting a $f_{\mathrm{m}}$ value of $20 \mathrm{~mm} \mathrm{~h}^{-1}$ as the 


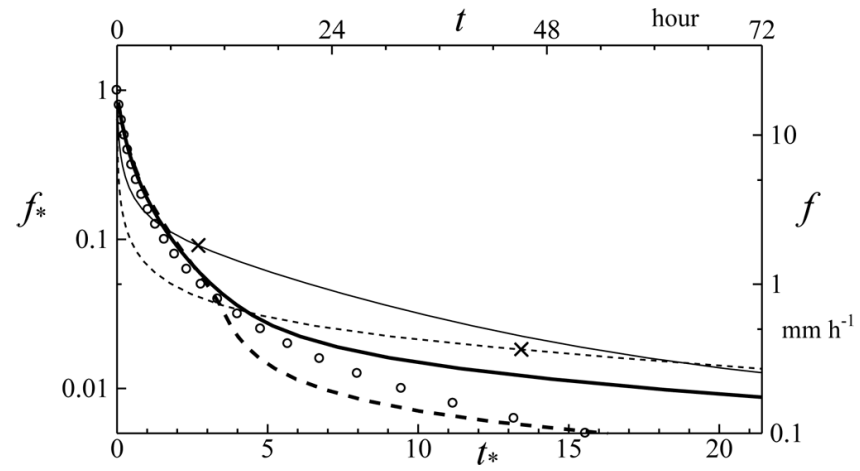

Fig. 7. Recession of the outflow rate from a sloping soil layer. Dimensionless scales are used for the bottom and left axes, and dimensional scales converted by $f_{\mathrm{m}}=20 \mathrm{~mm} \mathrm{~h}^{-1}$ are used for the top and right axes. Thin solid line: $\lambda=29.7$ and $\varepsilon=1$. Thin broken line: $\lambda=148.7$ and $\varepsilon=1$. Thick solid line: $\lambda=29.7$ and $\varepsilon=100$. Thick broken line: $\lambda=148.7$ and $\varepsilon=100 . \times$ : the outflow rate in which the saturation-excess overland flow is generated at the downslope end of the domain. $\bigcirc$ : calculated by the storage and outflow-rate relationship optimised for catchment KT, as also shown in Fig. 4.

criterion are also shown. The upper abscissa axis and right ordinate axis are scaled with the dimensional variables $f$ and $t$, whereas the lower and left axes are scaled with the dimensionless variables $f_{*}$ and $t_{*}$. The length scale $l$ and the timescale $T_{f}$ are converted to $67.24 \mathrm{~cm}$ by Eq. (B2) and $3.362 \mathrm{~h}$ by Eq. (C4), respectively, when $\theta_{\mathrm{S}}-\theta_{\mathrm{r}}$ is assumed to be 0.1 . The values of the other common parameters $\kappa, \delta, \omega$, and $\sigma$ were $5.4,1.49,30^{\circ}$, and 1.4 , respectively. The dimensional values of $\kappa$ and $\delta$ are respectively converted to $K_{\mathrm{S}}$ of $0.003 \mathrm{~cm} \mathrm{~s}^{-1}$ and $D$ of $1 \mathrm{~m}$. We used a parameter set of $\lambda=29.7$ and 148.7 (their dimensional values are converted to $L=20 \mathrm{~m}$ and $100 \mathrm{~m}$, respectively) with $\varepsilon=1$ and 100 for our recession-rate comparison. In addition to the calculation results, the simulation results using Eqs. (1) and (2) with parameters $p=0.3$ and $k=25$ that were optimised for a storm event in catchment KT at TEF, as shown in Fig. 4, are also plotted for the dimensional scale.

For the calculations with no macropore effect $(\varepsilon=1)$, saturation-excess overland flow was generated when the runoff rate exceeded the threshold indicated by the " $\times$ " mark in Fig. 7. The weight of the overland flow increased with the horizontal length of the sloping layer. In contrast, a high drainage capacity due to the macropore effect $(\varepsilon=100)$ reduced the rise in the water table and limited the occurrences of overland flow. When the macropore effect is large, the recession of the outflow rate depends little on the downslope flow in the $\mathrm{U}$ and $\mathrm{S}$ zones but is instead controlled mainly by the vertical water movement in the I zone. Both recession outflow rates with the macropore effect for $L=20 \mathrm{~m}$ and $100 \mathrm{~m}$ are similar to the recession of the runoff rate in KT in Fig. 7 regardless of a difference in the horizontal slope length, suggesting that the vertical water movement may play an important role in producing the stormflow recession characteristics as estimated from the observations (Montgomery and Dietrich, 2002).

\subsection{Summary of the sensitivity analysis}

The sensitivity analysis showed that the RBPI defined in Eq. (5) and the outflow recession represented by Eq. (6), both produced from soil layers with $\mathrm{HC}$ under QSS, had the following characteristics: the saturated downslope flow in the $\mathrm{S}$ zone and the saturation-excess overland flow had a large influence on RBPI when the macropore effect was not involved. This effect generally contributed to decreasing RBPI and reduced occurrences of overland flow by increasing the drainage capacity of downslope flow. Therefore, for a large macropore effect, RBPI was controlled mainly by the vertical unsaturated flow regardless of the slope length. A comparison of the recession flow with an observed result suggested the important role of the macropore effect in the production of quick recession outflow from the soil layer without the occurrence of saturation-excess overland flow. For the production of inflow/outflow waveform transmission from $\mathrm{HC}$ under QSS, we can thus conclude that the unsaturated and saturated flows were never isolated, considering the importance of their connection. Furthermore, the large drainage capacity of downslope flow played a key role in the confinement of $\mathrm{HC}$ inside the soil layer due to a reduction of saturationexcess overland flow.

\section{Discussion}

\subsection{Development of large drainage capacity accompanied by soil-layer evolution}

From the sensitivity analysis for a sloping soil layer, one of the key hydraulic conditions is a large drainage capacity of the downslope flow. If the drainage capacity is small, saturation-excess overland flow will be dominant in the stormflow generation process, as was also suggested by Freeze (1972). Considering this difference in the flow process, we now discuss why such a large drainage capacity can be found for catchments in active tectonic regions with largemagnitude storms. This "why-type" question for heterogeneity was raised by McDonnell et al. (2007), and its simple answer may be obtained from "the evolution process of the soil layer" against the severe erosional forces that exist in such regions, as discussed below.

We begin our discussion with a brief review of the tectonic and climatic conditions that exist in a region such as Japan. Topographic evolution on a timescale of more than $10^{5} \mathrm{yr}$ accompanied by strong erosional forces produces steep mountainous terrain (Montgomery and Brandon, 2002). Zeroorder catchments are created through the topographic evolution processes (Tsukamoto, 1973), and landslides occur more frequently in hollows with concave topography than 
in other areas of a catchment because of water convergence (Tsukamoto et al., 1982). However, analyses of cosmogenic nuclides have demonstrated that soil is constantly denuded, even along the ridge lines surrounding hollows in zero-order catchments (Heimsath et al., 1999), at speeds of about $0.1-1.0 \mathrm{~mm} \mathrm{yr}^{-1}$ in Japan (Matsushi and Matsuzaki, 2010). These studies suggest that soil produced from weathered bedrock continually moves from ridges down to concave hollows by gravity, which is similar to water movement but at a much longer timescale. Soil creep and small landslides probably contribute to this soil movement, although further studies are necessary to clarify this process. Hence, we can estimate a dynamic cycle of soil evolution processes, including landslides, on a shorter timescale of $10^{2}$ to $10^{4} \mathrm{yr}$ in a zero-order catchment than on a timescale of the topographic evolution. Soil-layer evolution may begin after a landslide only when soil particles on a denuded bedrock surface overcome the strong erosional forces from tectonic activity and heavy storms (Iida, 1999).

Two kinds of preconditions are absolutely necessary for soil-layer evolution. Soil particles produced from the denuded surface of weathered bedrock are so easily eroded by heavy rainfall that support by vegetation roots plays a key role in the soil evolution (Shimokawa, 1984). When a small denuded area is created by a landslide, vegetation and soil recover from the edge of the area through seeds supplied along with soil particles from surrounding areas (Matsumoto et al., 1995). Observations of bare land located on a granite mountain in Japan (Fukushima, 2006) suggested that in a widespread denuded landscape, also including ridgelines, the soil cannot be semi-eternally recovered. This is because the interplay between vegetation and soil fails because of a poor seed supply. The effect of vegetation roots on slope stability is quite important even for a thick soil layer because of the effects of both root penetration perpendicular to the sliding surface and three-dimensional root entanglement (Kitahara, 2010).

Saturation-excess and infiltration-excess overland flows certainly occur in gentle slope areas such as riparian zones (Gomi et al., 2010) and in local areas with a low surface permeability (Miyata et al., 2009), respectively. The acceleration of surface erosion and landslide initiation by the overland flows should be considered in quantifying the role of stormflow generation processes in active tectonic regions. The results of the sensitivity analysis in Sect. 4 showed a main role of saturation-excess overland flow in stormflow when the drainage capacity is not efficient for downslope flow in the soil. Then, the safety factor of a sloping soil layer decreases because the groundwater table rises to the ground surface (e.g. Sidle et al., 1985), accelerating landslide initiation. Hence, the efficiency of drainage capacity is critical for the sustainability of soil-layer evolution, at least in steep hollows where water converges. Because the effect of erosional forces is consistent throughout the period of soil-layer evolution, it has to be accompanied by the development of an efficient drainage system. Only a few studies have discussed how such a system with a large drainage capacity might develop (Tsukamoto and Ohta, 1988). It may be that the production of a soil block reinforced by a vegetation root system and the erosion of fine soil particles beneath the ground could progress simultaneously, resulting in increased heterogeneities in the permeability of the soil layer.

From the viewpoint of the longer timescale of topographic evolution, however, soil-layer evolution cannot continue forever because the safety factor will decrease with the growth of the soil layer itself (Sidle et al., 1985) and with the increased elevation difference between the ridgeline and streambed caused by the uplifting of mountain body and the erosion of streambed (Montgomery and Brandon, 2002). The robustness of soil-layer evolution will eventually fail, and once a landslide occurs, the large amount of water stored within the soil will be released instantaneously, sometimes causing fluidisation of the collapsed soil and debris flow (Takahashi, 1978). Conversely, as long as the soil layer continues to evolve without landslide occurrences, most of the rainwater will be confined within the soil layer during a storm, even one with a large magnitude. A large drainage capacity of the downslope flow plays a key role in this confinement, which is necessary for continuous soil-layer evolution, and ensures that simple and quick stormflow responses will be produced from HC under QSS created inside the soil layer. Thus, both the development of an efficient drainage system and reinforcement by a vegetation root system may be associated with the evolution of the soil layer.

\subsection{A possible modelling strategy}

According to our discussion, soil-layer evolution may control complex and heterogeneous spatial distributions of topographic and soil properties; these include systems with large drainage capacity consisting of macropores or natural pipes developed at least in the water-converging portion of a zero-order catchment. However, the evolution may also allow for the simple stormflow responses empirically simulated by TANK in Sect. 2.4. Both phenomena are commonly produced from the geophysical process of soil-layer evolution, but it is not easy to find a direct causal relationship between them because both may be mediated by a long evolutionary history. For example, if the development of macropores tends to be encouraged in clayey soil rather than in sandy soil through a long history of soil-layer evolution, the dependence of stormflow responses on the soil hydraulic properties might be quite different from that expected from idealised homogeneous properties (Weiler et al., 2006). If the drainage capacity of the downslope flow is so large that the storage change in response to the flow rate is negligible compared to that in the vertical unsaturated flow, the dependence of the RBPI values on slope length may almost disappear, as shown in the right panel of Fig. 6; these values may also differ from those predicted by a distributed runoff model in which the 
stormflow component is represented by only a downslopeflow component (Ishihara and Takasao, 1964; Troch et al., 2003). The dependence of stormflow responses on unsaturated vertical flow has often been discussed from on-site observations (Montgomery and Dietrich, 2002) and from theoretical considerations (Tani, 1985a; Kosugi, 1999). As a result, parameterisation of catchment properties must consider the historical evolution of the soil layer for distributed runoff models of active tectonic regions.

An additional insight into the evolution process provides another suggestion for predicting large-magnitude stormflow responses. As long as the stormflow is confined within the soil layer, as explained in Sect. 5.1, the characteristics of waveform transmission between the rainfall intensity and stormflow rate will be consistent for various storms with large magnitudes. Hence, this consistency may provide a useful clue to a prediction of stormflow responses in rare storm events never before observed because the validity of model predictions may be guaranteed except in the case of landslide occurrences.

Finally, in addition to these fundamental subjects, to better predict stormflow, more comparative studies are needed to identify which properties stormflow responses are dependent on. Although the dependences deductively introduced from the surface topography as usually used in distributed runoff models might be often regarded doubtful by on-site observations in active tectonic regions (Montgomery and Dietrich, 2002; Weiler et al., 2006; McDonnell et al., 2007), only a few studies have focused on intercomparison (Negley and Eshleman, 2006; Uchida et al., 2006; Tani et al., 2012). Since many observations of stormflow responses have already been obtained, a higher priority should be given to an inductive detection of the dependences on catchment properties by the intercomparison of these data to apply the results to runoffmodel parameterisations.

\section{Conclusions}

Many distributed runoff models have been developed, but it is still difficult to predict stormflow responses in catchments with no observational data used for the parameter calibration and to predict responses to storms of larger magnitude than have ever been observed even in catchments with observational data. To address such problems, this paper proposes the simple idea that stormflow responses reflect the soil-layer evolution process.

This idea was originally based on individual observational results on stormflow responses and their mechanisms, and the review suggested that HC under QSS played a key role in the production of these responses. The following new findings were obtained from this concept. (1) Stormflow responses were simply produced from HC under QSS when the stormflow-contribution area was spatially invariable due to the sufficient amount of rainfall supply. (2) The sensitivities of stormflow response for a sloping soil layer to the soil and topographic properties were examined using a new similarity framework with six dimensionless parameters when a steadystate flow rate was given as a criterion. (3) The examination showed that a large drainage capacity played a key role in the quick inflow/outflow transmission, and contributed to a reduction of saturation-excess overland flow and a confinement of water flow within the soil layer. (4) Discussion on the soil-layer evolution suggested that this confinement was needed for the evolution against strong erosional forces in active tectonic regions with large-magnitude storms.

On the basis of these findings, we have proposed two strategies for stormflow prediction: a parameterisation of catchment properties in consideration of the historical soillayer evolution, and comparative hydrology for inductively evaluating dependences of stormflow responses on catchment properties. These ideas presented in this paper can therefore provide a clue for improving a prediction of stormflow responses by distributed runoff models from the catchment properties. As a result, because complex catchment properties and simple stormflow responses were created by a long-term soil-evolution process, the development of distributed runoff models should focus their parameterisation strategies on the underground structure rather than the surface soil topography. This concept may impose a paradigm shift in the prediction of stormflow responses in active tectonic regions.

\section{Appendix A}

\section{Fundamental equations for sensitivity analysis}

Like Tani (2008), we also assess a sloping soil layer with constant depth and homogeneous hydraulic properties using a two-dimensional form of the Richards equation. The origin is placed at the upslope end of the surface of the soil layer, and the $x$ axis and $z$ axis are positive in the horizontal and downward directions, respectively (Fig. 5). For our calculation, we use the upslope portion of a semi-infinite soil layer with horizontal length $L$ and vertical depth $D$ to avoid the local influences of specific boundary conditions such as seepage faces. Because only a steady-state response to rainfall with a constant intensity is analysed here, the fundamental equation is given as

$$
\frac{\partial}{\partial x}\left(K \frac{\partial \psi}{\partial x}\right)+\frac{\partial}{\partial z}\left\{K\left(\frac{\partial \psi}{\partial z}-1\right)\right\}=0,
$$

where $K$ is the hydraulic conductivity and $\psi$ is the pressure head.

As the surface boundary condition, rainfall with a constant intensity (equal to the outflow rate per unit slope length $f$ because of the steady state) is applied to the sloping soil layer. Infiltration-excess overland flow is eliminated by setting $f$ lower than the saturated hydraulic conductivity. The 
boundary condition along the slope surface is written as

$q_{z}=f$ when $\psi<0$ at $z=x \tan \omega, x \geq 0$,

where $\omega$ is the slope angle. When $\psi$ reaches zero at the surface, a constant pressure condition $(\psi=0)$ is imposed to saturation-excess overland flow. For the other boundary conditions, we assume that no water flow occurs along the bottom of the permeable soil layer and across the upslope end. Accordingly,

$q_{z}=0$ at $z=x \tan \omega+D, x \geq 0$,

$q_{x}=0$ at $x=0,0 \leq z \leq D$.

Tani (2008) proposed an approximation for the steadystate distribution of pressure head based on the DupuitForchheimer assumption (Beven, 1981) and confirmed its agreement with solutions by the Richards equation for a steep sloping soil layer. We also use this approximation because it can aid in understanding of the structure of the flow components. Three zones can be categorised as shown in Fig. 5: the I zone for the vertical unsaturated flow starts at $x=0$ but ends at $x=x_{\mathrm{iu}}$, after which the $\mathrm{U}$ zone for the downslope unsaturated flow grows up to the soil-layer surface. The $\mathrm{S}$ zone for the downslope saturated flow starts at $x_{\mathrm{us}}$, where the unsaturated flow rate within the $U$ zone reaches the limitation. Saturation-excess overland flow starts at $x_{\text {so }}$ because the saturated downslope rate finally reaches the maximum. The indicators $x_{\mathrm{iu}}, x_{\mathrm{us}}$, and $x_{\mathrm{so}}$ for the categorisation can be calculated from the approximation and their dimensionless forms will be described later in Appendix B.

For soil physical properties controlling water retention and permeability, Kosugi's (1996, 1997a, b) equations derived from log-normal soil pore distributions are used:

$$
\begin{aligned}
\theta & =\left(\theta_{\mathrm{s}}-\theta_{\mathrm{r}}\right) S_{\mathrm{e}}+\theta_{\mathrm{r}} \\
& =\left(\theta_{\mathrm{s}}-\theta_{\mathrm{r}}\right) Q\left[\frac{\ln \left(\psi / \psi_{\mathrm{m}}\right)}{\sigma}\right]+\theta_{\mathrm{r}} \text { for } \psi<0, \\
\theta & =\theta_{\mathrm{s}} \text { for } \psi \geq 0, \\
K_{0} & =K_{\mathrm{s}} K_{*} .
\end{aligned}
$$

Here $\theta$ is the volumetric water content; $S_{\mathrm{e}}$ is the effective saturation; $\theta_{\mathrm{s}}$ and $\theta_{\mathrm{r}}$ are the saturated and residual volumetric water contents, respectively; $\psi_{\mathrm{m}}$ is the median pressure head corresponding to the median pore radius; $\sigma$ is the standard deviation of the log-transformed soil pore radius $(\sigma>0)$, which characterises the width of the pore-size distribution; $Q$ is the complementary normal distribution function,

$Q(y)=(2 \pi)^{-0.5} \int_{y}^{\infty} \exp \left(\frac{-u^{2}}{2}\right) \mathrm{d} u ;$

$K_{0}$ is the hydraulic conductivity given by Kosugi's equation, which is distinguished from $K$ because of the involvement of the macropore effect described later; and $K_{*}$ is the relative unsaturated hydraulic conductivity, defined as

$$
\begin{aligned}
K_{*} & =\left[Q\left\{\frac{\ln \left(\psi / \psi_{\mathrm{m}}\right)}{\sigma}\right\}\right]^{1 / 2} \\
& \times\left[Q\left\{\frac{\ln \left(\psi / \psi_{\mathrm{m}}\right)}{\sigma}+\sigma\right\}\right]^{2} \text { for } \psi<0 \\
K_{*} & =1 \text { for } \psi \geq 0 .
\end{aligned}
$$

Therefore, the relationships of volumetric water content and unsaturated hydraulic conductivity to pressure head described in above equations are represented by parameters including $\theta_{\mathrm{s}}, \theta_{\mathrm{r}}, K_{\mathrm{s}}, \psi_{\mathrm{m}}$, and $\sigma$. This means that the effects of soil physical properties on the hydraulics of a sloping soil layer can be assessed by a sensitivity analysis of these five parameters. However, this procedure may still be too tangled to extract the essence of each effect, making a simpler parameter set desirable. First, $\theta_{\mathrm{s}}$ and $\theta_{\mathrm{r}}$ can be removed using the effective saturation, $S_{\mathrm{e}}$, because of their linear contribution, and the retention and hydraulic properties can be written in terms of $K_{\mathrm{s}}, \psi_{\mathrm{m}}$, and $\sigma$. In addition, because the saturated hydraulic conductivity $K_{\mathrm{s}}$ may be dependent on the soil pore distribution, $K_{\mathrm{s}}$ and $\psi_{\mathrm{m}}$ can be connected. Kosugi (1997a) proposed the following functional relationship based on the proportional relationship of $K_{\mathrm{s}}$ to the square of the arithmetic mean of pore radius $r_{\mathrm{a}}$.

$K_{\mathrm{s}}=A r_{\mathrm{a}}^{2}=A r_{\mathrm{m}}^{2} \exp \left(\sigma^{2}\right)$.

Here, $r_{\mathrm{m}}$ is the median pore radius and $A$ is a proportionality constant. The relationship of capillary rise to pore radius is expressed as

$\psi=-\frac{2 \gamma \cos \eta}{\rho g r}$,

where $\gamma$ is the surface tension between the water and air, $\eta$ is the contact angle, $\rho$ is the density of water, and $g$ is the acceleration due to gravity. Substituting Eq. (A12) into Eq. (A11) yields

$K_{\mathrm{S}}=A\left[\frac{2 \gamma \cos \eta}{\rho g}\right]^{2} \frac{1}{\psi_{\mathrm{a}}^{2}}=\frac{B}{\psi_{\mathrm{a}}^{2}}=\frac{B \exp \left(\sigma^{2}\right)}{\psi_{\mathrm{m}}^{2}}$,

where $\psi_{\mathrm{a}}$ is the pressure head corresponding to $r_{\mathrm{a}}$. Kosugi (1997b) estimated the value of $B$ $\left[=A\{(2 \gamma \cos \eta) /(\rho g)\}^{2}\right]$ as a constant value of $10^{0.4} \mathrm{~cm}^{3} \mathrm{~s}^{-1}$ from a data set of soil hydraulic properties (Mashimo, 1960). As the parameter representing soil water retention, it is better to select $\psi_{\mathrm{a}}$ than $\psi_{\mathrm{m}}$ because $K_{\mathrm{s}}$ is not related to $\sigma$, only $\psi_{\mathrm{a}}$. Hence, the soil physical properties can be represented by only two parameters.

As macropores play an important role in the hydraulics in our soil layer, their effect was parameterised here using a method proposed by Tani (2008):

$K=K_{0}$ for $\psi<0$,

$K=\varepsilon \times K_{\mathrm{s}}$ for $\psi \geq 0$, 
where $\varepsilon$ represents an empirical parameter for the macropore effect. This parameterisation assumes that the macropore effect functions only within the saturated zone.

\section{Appendix B}

\section{Similarity framework of the pressure-head distribution}

A method using a similarity framework has been often applied to runoff processes to generalise an assessment of the effects of catchment properties (Takagi and Matsubayashi, 1979; Harman and Sivapalan, 2009). We also introduce such a method to assess the dependence of RBPI on the properties of slope topography and soil physics. Because RBPI is defined in Eq. (5) by the increase/decrease in $V$ in response to a small increase/decrease in the outflow rate $f$ around the average $f_{\mathrm{m}}, f_{\mathrm{m}}$ was selected as the standard for our dimensionless form. The saturated hydraulic conductivity $K_{\mathrm{S}}$ was made dimensionless as

$\kappa=\frac{K_{\mathrm{s}}}{f_{\mathrm{m}}}$.

The dimensionless ratio between the depth of the soil layer and a parameter with the dimension of length representing the soil water retention characteristic curve has often been used for a similarity framework of saturatedunsaturated flow (Verma and Brutsaert, 1970; Tani, 1982, 1985a, b; Suzuki, 1984) because this ratio is a key controller of the relative importance of capillaries in the vertical dimension of the permeable domain (Brutsaert, 2005). Because $f_{\mathrm{m}}$ is used as the standard in our analysis, the parameter $l$ was selected for the length scale in reference to the relationship between $K_{\mathrm{s}}$ and $\psi_{\mathrm{a}}$ in Eq. (A13) with the empirical $B$ value of $10^{0.4}$ (Kosugi, 1997b)

$l=10^{0.2} / \sqrt{f_{\mathrm{m}}}$.

The parameter $\psi_{\mathrm{a}}$ in Eq. (A13) is made dimensionless by substituting Eqs. (B1) and (B2) into Eq. (A13), yielding

$\psi_{\mathrm{a}_{*}}=\psi_{\mathrm{a}} / l=-\sqrt{1 / \kappa}$.

The soil physical properties in our similarity framework are represented by only two dimensionless parameters, $\kappa$ and $\sigma$.

The rainfall intensity (= outflow rate per unit slope length because of steady state) $f$, pressure head $\psi$, horizontal axis $x$, vertical axis $z$, horizontal soil-layer length $L$, and depth $D$ of the soil layer are made dimensionless as

$$
\begin{aligned}
f_{*} & =f / f_{\mathrm{m}}, \\
\psi_{*} & =\psi / l, \\
x_{*} & =x / l, \\
z_{*} & =z / l, \\
\lambda & =L / l, \\
\delta & =D / l .
\end{aligned}
$$

When analysing the spatial distribution of pressure head in this similarity framework using six dimensionless parameters $-\omega, \lambda, \delta, \kappa, \sigma$, and $\varepsilon$ - we can generally make an intercomparison of hydraulic characteristics within soil layers with various topographic and soil properties in a steady state with a flow rate of $f_{\mathrm{m}}$ as a criterion.

Indicators of the flow categorisation mentioned in Appendix A and illustrated in Fig. 5 can be calculated from the relationship of vertical pressure-head distribution to the downslope flow rate at a horizontal distance (Tani, 2008) because a hydrostatic distribution based on the DupuitForchheimer assumption is applied in our approximation. The dimensionless forms are described here as

$$
\begin{aligned}
& x_{\mathrm{iu} *}=\int_{\psi_{\mathrm{f} *}}^{\psi_{\mathrm{f} *}+\delta \cos ^{2} \omega} K_{*} \mathrm{~d} \psi_{*} \frac{\kappa \tan \omega}{f_{*}} \text { for } \alpha<1 \\
& x_{\mathrm{iu} *}=\left\{\int_{\psi_{\mathrm{f} *}}^{0} K_{*} \mathrm{~d} \psi_{*}+\varepsilon\left(\delta \cos ^{2} \omega+\psi_{\mathrm{f} *}\right)\right\} \frac{\kappa \tan \omega}{f_{*}}
\end{aligned}
$$$$
\text { for } \alpha \geq 1 \text {, }
$$

$x_{\mathrm{us} *}=\int_{-\delta \cos ^{2} \omega}^{0} K_{*} \mathrm{~d} \psi_{*} \frac{\kappa \tan \omega}{f_{*}}$ for $\alpha<1$,

$x_{\mathrm{us} *}=\int_{\psi_{\mathrm{f} *}}^{0} K_{*} \mathrm{~d} \psi_{*} \frac{\kappa \tan \omega}{f_{*}}$ for $\alpha \geq 1$,

$x_{\mathrm{SO} *}=\frac{\delta \varepsilon \kappa \sin \omega \cos \omega}{f_{*}}$,

where the relative hydraulic conductivity $K_{*}$ is calculated as follows by substituting Eq. (B3) into Eq. (A9):

$$
\begin{aligned}
K_{*} & =\left[Q\left\{\frac{\ln \left(-\psi_{*} \sqrt{\kappa}\right)}{\sigma}-\frac{\sigma}{2}\right\}\right]^{1 / 2} \\
& \times\left[Q\left\{\frac{\ln \left(-\psi_{*} \sqrt{\kappa}\right)}{\sigma}+\frac{\sigma}{2}\right\}\right]^{2} .
\end{aligned}
$$

The pressure head $\psi_{\mathrm{f}_{*}}$ included in the above equations represents the dimensionless form of $\psi_{\mathrm{f}}$, a constant pressurehead value in response to $f$ in the I zone where the vertical flow is governed by only the gradient of gravity force $(\mathrm{Ru}-$ bin and Steinhardt, 1963). This relationship can be written in dimensional form as

$$
K\left(\psi_{\mathrm{f}}\right)=f .
$$

Hence, $\psi_{\mathrm{f}_{*}}$ is inversely calculated by

$K_{*}\left(\psi_{\mathrm{f} *}\right)=f_{*} / \kappa$.

The pressure head in the I zone is

$\psi_{*}=\psi_{\mathrm{f} *}$. 
A dimensionless number $\alpha$ controlling the structure of categorisation within a soil layer is defined as

$\alpha=-\frac{\delta \cos ^{2} \omega}{\psi_{\mathrm{f} *}}$.

In the $\mathrm{U}$ and $\mathrm{S}$ zones, a hydrostatic distribution based on the Dupuit-Forchheimer assumption is applied for a vertical profile as

$\psi_{*}=\psi_{\mathrm{b} *}-\left(\delta-z_{*}\right) \cos ^{2} \omega-x_{*} \sin \omega \cos \omega$,

where $\psi_{\mathrm{b}_{*}}$ is the pressure head at the bottom of the soil layer. The value of $\psi_{\mathrm{b}_{*}}$ is inversely calculated from the downslope flow rate across the vertical soil-layer profile at a horizontal distance of $x_{*}$. This flow rate can be obtained by integrating the supplied vertical flow rate $f_{*}$ from the upslope end $\left(x_{*}=0\right)$ to $x_{*}$ because the system is in a steady state. The following equations can be used for the calculation according to the categorisation of the pressure-head distribution described in Eqs. (B10) to (B14):

$$
\begin{aligned}
& \int_{\psi_{\mathrm{f} *}}^{\psi_{\mathrm{b} *}} K_{*} \mathrm{~d} \psi_{*}=\frac{f_{*} x_{*}}{\kappa \tan \omega} \text { for } x_{*} \leq x_{\mathrm{iu} *} \text { and } \alpha<1 \\
& \text { or } x_{*} \leq x_{\mathrm{us} *} \text { and } \alpha \geq 1 \\
& \quad \int_{\psi_{\mathrm{b} *}} K_{*} \mathrm{~d} \psi_{*}=\frac{f_{*} x_{*}}{\kappa \tan \omega} \text { for } x_{\mathrm{iu} *}<x_{*} \leq x_{\mathrm{us} *} \\
& \psi_{\mathrm{b} *}-\delta \cos ^{2} \omega \\
& \int_{\psi_{\mathrm{f} *}}^{0} K_{*} \mathrm{~d} \psi_{*}+\varepsilon \psi_{\mathrm{b} *}=\frac{f_{*} x_{*}}{\kappa \tan \omega} \text { for } x_{\mathrm{us} *}<x_{*} \leq x_{\mathrm{iu} *} \\
& \text { and } \alpha \geq 1, \\
& \quad 0 \\
& \int_{\psi_{\mathrm{b} *}-\delta \cos ^{2} \omega}^{0} K_{*} \mathrm{~d} \psi_{*}+\varepsilon \psi_{\mathrm{b} *}=\frac{f_{*} x_{*}}{\kappa \tan \omega} \text { for } x_{\mathrm{us} *}<x_{*} \leq x_{\mathrm{so} *} \\
& \text { and } \alpha<1, \\
& \text { or } x_{\mathrm{iu} *}<x_{*} \leq x_{\mathrm{so} *} \text { and } \alpha \geq 1 \text {. }
\end{aligned}
$$

\section{Appendix C}

\section{Similarity framework of the index of runoff buffering potential (RBPI)}

To assess the RBPI for the sloping soil layer, the water storage volume per unit drainage area $V$ is represented as the total volumetric water content $\theta$ per unit of horizontal length integrated over the whole soil layer:

$$
V=\frac{1}{L} \int_{0}^{L} \int_{x \tan \omega}^{x \tan \omega+D} \theta \mathrm{d} z \mathrm{~d} x
$$

For our nondimensionalisation described in Appendix B, the dimensionless storage volume $V_{*}$ is obtained as

$V_{*}=\frac{V-D \theta_{\mathrm{r}}}{l\left(\theta_{\mathrm{s}}-\theta_{\mathrm{r}}\right)}=\frac{\int_{0}^{\lambda} \int_{x_{*} \tan \omega}^{x_{*} \tan \omega+\delta} S_{\mathrm{e}} \mathrm{d} z_{*} \mathrm{~d} x_{*}}{\lambda}$.

The RBPI for $f_{\mathrm{m}}$ in Eq. (5) is made dimensionless into $\mathrm{RBPI}_{*}$ for the unity as

$\left.\left.\operatorname{RBPI}_{*}\right|_{f_{*}=1} \equiv \frac{\mathrm{d} V_{*}}{\mathrm{~d} f_{*}}\right|_{f_{*}=1}=\left.\frac{1}{T_{\mathrm{f}}} \frac{\mathrm{d} V}{\mathrm{~d} f}\right|_{f_{\mathrm{m}}}=\left.\frac{1}{T_{\mathrm{f}}} \mathrm{RBPI}\right|_{f_{\mathrm{m}}}$,

where $T_{\mathrm{f}}$ is the timescale for the nondimensionalisation derived by submitting Eqs. (B4) and (C2) into Eq. (C3):

$T_{\mathrm{f}}=\frac{l\left(\theta_{\mathrm{s}}-\theta_{\mathrm{r}}\right)}{f_{\mathrm{m}}}$.

This scale is the time necessary for filling the effective pores in a standard soil depth of $l$ with a standard flow rate of $f_{\mathrm{m}}$. Equation (6) representing the recession gradient is made dimensionless as

$\frac{\mathrm{d} f_{*}}{\mathrm{~d} t_{*}}=\frac{-f_{*}}{\mathrm{~d} V_{*} / \mathrm{d} f_{*}}=\frac{-f_{*}}{\mathrm{RBPI}_{*}}$,

where $t_{*}$ is the dimensionless time defined as

$t_{*}=t / T_{\mathrm{f}}$

The recession flow rate from the starting rate of $f_{*}=1$ ( $f=f_{\mathrm{m}}$ in the dimensional form) can be obtained by the numerical integral using Eq. (C5).

Acknowledgements. I express my appreciation to Suzanne Anderson (University of Colorado, Boulder) for providing valuable data on the sprinkler experiment conducted in CB1 with useful comments. Data from TEF were obtained while I worked for the Forestry and Forest Products Research Institute, and I wish to thank all the staff concerned. I acknowledge Kooiti Masuda (Research Institute for Global Change, Japan Agency for Marine-Earth Science and Technology) because I learned much about the concept of a quasi-steady-state system from his personal website. This study was supported by the Japan Society for the Promotion of Science (JSPS) for KAKENHI grant number 23221009, titled "Prediction of catchment runoff changes based on elucidating a nested structure consisting of the developments of topography, soil, and vegetation".

Edited by: M. Sivapalan 


\section{References}

Anderson, S. P., Dietrich, W. E., Montgomery, D. R., Torres, R., Conrad, M. E., and Loague, K.: Subsurface flow paths in a steep, unchanneled catchment, Water Resour. Res., 33, 26372653, 1997.

Betson, R. P. and Ardis Jr., C. V.: Implications for modelling surface-water hydrology, in: Hillslope Hydrology, edited by: Kirkby, M. J., Wiley \& Sons, Chichester, UK, 295-323, 1978.

Beven, K.: Kinematic downslope flow, Water Resour. Res., 17, 1419-1424, 1981.

Beven, K. and Kirkby, M. J.: A physically based, variable contributing area model of basin hydrology, Hydrol. Sci. Bull., 24, 43-69, 1979.

Brutsaert, W.: Hydrology: An Introduction, Cambridge Univ., Cambridge, ISBN 13 978-0-521-82479-8, 366-382, 2005.

Dunne, T.: Relation of field studies and modeling in the prediction of storm runoff, J. Hydrol., 65, 25-48, 1983.

Dunne, T. and Black, R. D.: Partial-area contributions to storm runoff in a small New England watershed, Water Resour. Res., 6, 1296-1311, 1970.

Ebel, B. R., Loague, K., Dietrich, W. E., Montgomery, D. R., Torres, R., Anderson, S. P., and Giambelluca, T. W.: Near-surface hydrologic response for a steep, unchanneled catchment near Coos Bay, Oregon: 1. Sprinkled experiments, Am. J. Sci., 907, 678708, doi:10.2475/04.2007.02, 2007.

Freeze, R. A.: Role of subsurface flow in generating surface flow 2. Upstream source areas, Water Resour. Res., 8, 1272-1283, 1972.

Fukushima, Y.: The role of forest on the hydrology on headwater wetlands, in: Environmental Role of Wetlands in Headwaters, edited by: Krecek, J. and Haigh, M., Springer, Dordrecht, ISBN 1-4020-4226-4, 17-47, 2006.

Fukushima, Y. and Suzuki, M.: A model for river flow forecasting for a small mountain catchment, Hydrol. Process., 2, 167-185, 1988.

Gabrielli, C. P., McDonnell, J. J., and Jarvis, W. T.: The role of bedrock groundwater in rainfall-runoff response at hillslope and catchment scales, J. Hydrol., 450-451, 117-133, doi:10.1016/j.jhydrol.2012.05.023, 2012.

Gomi, T., Asano, Y., Uchida, T., Onda, Y., Sidle, R.C., Miyata, S., Kosugi, K., Mizugaki, S., Fukuyama, T., and Fukushima, T.: Evaluation of storm runoff pathways in steep nested catchments draining a Japanese cypress forest in central Japan: a hydrometric, geochemical, and isotopic approaches, Hydrol. Process., 24, 550-566. doi:10.1002/hyp.7550, 2010.

Harman, C. and Sivapalan, M.: A similarity framework to assess controls on shallow subsurface flow dynamics in hillslopes, Water Resour. Res., 45, W01417, doi:10.1029/2008WR007067, 2009.

Heimsath, A. M., Dietrich, W. E., Nishiizumi K., and Finkel, R. C.: Cosmogenic nuclides, topography, and the spatial variation of soil depth, Geomorphology, 27, 151-172, 1999.

Hewlett, J. D. and Hibbert, A. R.: Factors affecting the response of small watersheds to precipitation in humid areas, in: International Symp. Forest Hydrology, edited by: Sopper, W. E. and Lull, H. W., Pergamon, Oxford, 275-290, 1968.

Horton, R. E.: The role of infiltration in the hydrologic cycle, Trans. Am. Geophys. Union, 14, 446-460, 1933.

Hosoda, I.: Measurement on groundwater level variations within the bedrock in a hillslope underlain by Palaeozoic formations, Pro- ceedings of 2008 Annual Conference, Japan Society of Hydrology and Water Resources, 172-173, 2008 (in Japanese. The title is translated into English by the present author).

Iida, T.: A stochastic hydro-geomorphological model for shallow landsliding due to rainstorm, Catena 34, 293-313, doi:10.1016/S0341-8162(98)00093-9, 1999.

Ishihara, T. and Takasao, T.: A study on the transformation system during flood runoff, Bull. Disaster Prev. Res. Inst., Kyoto Univ., 7, 265-279, 1964 (in Japanese with English abstract).

Iwagaki, Y.: Fundamental studies on the runoff analysis by characteristics, Disaster Prev. Res. Inst., Kyoto Univ., Kyoto, 25 pp., 1955.

Kadoya, M. and Fukushima, A.: Concentration time of flood in small or medium river basins, Bull. Disaster Prev. Res. Inst., Kyoto Uv., 19B-2, 143-152, 1976 (in Japanese with English abstract).

Katsuyama, M., Tani, M., and Nishimoto, S.: Connection between streamwater mean residence time and bedrock groundwater recharge/discharge dynamics in weathered granite catchments, Hydrol. Process., 24, 2287-2299, doi:10.1002/hyp.7741, 2010.

Kimura, T.: The Flood Runoff Analysis Method by the Storage Function Model, The Public Works Research Institute, Ministry of Construction, Tokyo, 1961 (in Japanese. The title is translated into English by the present author).

Kitahara, H.: Effect of tree root systems on slope stability, Suirikagaku, 311, 11-37, 2010 (in Japanese. The title is translated into English by the present author).

Kosugi, K.: Lognormal distribution model for unsaturated soil hydraulic properties, Water Resour. Res., 32, 2697-2703, 1996.

Kosugi, K.: Effect of pore radius distribution of forest soils on vertical water movement in soil profile, J. Japan Soc. Hydrol. Water Resour., 10, 226-237, 1997a.

Kosugi, K.: New diagrams to evaluate soil pore radius distribution and saturated hydraulic conductivity of forest soil, J. For. Res. 2, 95-101, 1997b.

Kosugi, K.: New index to evaluate water holding capacity of forest soils, J. Jpn. For. Soc., 81, 225-235, 1999 (in Japanese with English abstract).

Kosugi, K., Katsura, S., Katsuyama, M., and Mizuyama, T.: Water flow processes in weathered granitic bedrock and their effects on runoff generation in a small headwater catchment, Water Resour. Res., 42, W02414, doi:10.1029/2005WR004275, 2006.

Kosugi, K., Fujimoto, M., Katsura, S., Kato, H., Sando, Y., and Mizuyama, T.: Localized bedrock aquifer distribution explains discharge from a headwater catchment, Water Resour. Res., 47, W07530, doi:10.1029/2010WR009884, 2011.

Mashimo, Y.: Studies on the physical properties of forest soil and their relation to the growth of sugi (Cryptomeria japonica) and hinoki (Chamaecyparis obtusa), Forest Soils of Japan Report 11, Government Forest Experimental Station, Tokyo, 182, 1960 (in Japanese with English abstract).

Matsumoto, M., Shimokawa, E., and Jitousono, T.: A natural recovegetation process on shallow landslide scars in deep weathering granite slopes, Res. Bull. Kagoshima Univ. For., 23, 55-79, 1995 (in Japanese with English abstract).

Matsushi, Y. and Matsuzaki, H.: Denudation rates and threshold slope in a granitic watershed, central Japan, Nuclear Instr. Methods Phys. Res. B, 268, 1201-1204, 2010. 
McDonnell, J. J.: A rationale for old water discharge through macropores in a steep, humid catchment, Water Resour. Res., 26, 2821-2832, 1990.

McDonnell, J. J.: Where does water go when it rains? Moving beyond the variable source area concept of rainfall-runoff response, Hydrol. Process., 17, 1869-1875, 2003.

McDonnell, J. J., Sivapalan, M., Vaché, K., Grant, G., Haggerty, R., Hinz, C., Hooper, R., Kirchnner, J., Roderick, M. L., Selker, J., and Weiler, M.: Moving beyond heterogeneity and process complexity: A new vision for watershed hydrology, Water Resour. Res., 43, W07301, doi:10.1029/2006WR005467, 2007.

Meadows, D. H.: Thinking in Systems: A Primer, edited by: Wright, D., Earthscan, London, 218, ISBN 978-1-84407-726-7, 2008.

Michaelides, K. and Chappell, A.: Connectivity as a concept for characterising hydrological behaviour, Hydrol. Process., 23, 517-522, doi:10.1002/hyp.7214, 2009.

Miyata, S., Kosugi, K., Gomi, T., Sidle, R. C., and Mizuyama, T.: Effects of forest floor coverage on overland flow and soil erosion on hillslopes in Japanese cypress plantation forests, Water Resour. Res., 45, W06402, doi:10.1029/2008WR007270, 2009.

Montgomery, D. R. and Brandon, M. T.: Topographic controls on erosion rates in tectonically active mountain ranges, Earth Planet. Sci. Lett., 201, 481-489, doi:10.1016/S0012-821X(02)00725-2, 2002.

Montgomery, D. R. and Dietrich, W. E.: Runoff generation in a steep, soil-mantled landscape, Water Resour. Res., 38, 1168, doi:10.1029/2001WR000822, 2002.

Montgomery, D. R., Dietrich, W. E. Torres, R., Anderson, S. P., Heffner, J. T., and Loague, K.: Piezometric response of a steep unchanneled valley to natural and applied rainfall, Water Resour. Res., 33, 91-109, 1997.

Mosley, M. P.: Streamflow generation in a forested watershed, New Zealand, Water Resour. Res., 15, 795-806, 1979.

Negley, T. L. and Eshleman, K. N.: Comparison of stormflow responses of surface-mined and forested watersheds in the Appalachian Mountains, USA, Hydrol. Process., 20, 3467-3483, doi:10.1002/hyp.6148, 2006.

Nieber, J. L. and Sidle, R. C.: How do disconnected macropores in sloping soils facilitate complex how?, Hydrol. Process., 24, 1582-1594, doi:10.1002/hyp.7633, 2010.

Okamoto, Y.: The studies on the runoff phenomena and processes of mountain forest drainage basins in Japan, Trans. of JSCE, 280, 51-66, 1978 (in Japanese with English abstract).

Oldham, C. E., Farrow, D. E., and Peiffer, S.: A generalized Damköhler number for classifying material processing in hydrological systems, Hydrol. Earth Syst. Sci., 17, 1133-1148, doi:10.5194/hess-17-1133-2013, 2013.

O'Loughlin, E. M.: Prediction of surface saturation zones in natural catchments by topographic analysis, Water Resour. Res., 22, 794-804, 1986.

Pearce, A. J., Stewart, M. K., and Sklash, M. G.: Storm runoff generation in humid headwater catchments: 1 . Where does the water come from?, Water Resour. Res., 22, 1263-1272, 1986.

Pinder, G. F. and Jones, J. F.: Determination of the ground-water component of peak discharge from the chemistry of total runoff, Water Resour. Res., 5, 438-445, 1969.

Rubin, J. and Steinhardt, R.: Soil water relations during rain infiltration: I. Theory, Soil Sci. Soc. Amer. Proc., 27, 246-251, 1963.
Shimizu, T.: Relation between scanty runoff from mountainous watershed and geology, slope and vegetation, Bull. For. For. Prod. Res. Inst., 310, 109-128, 1980 (in Japanese with English abstract).

Shimokawa, E.: A natural recovery process of vegetation on landslide scars and landslide periodicity in forested drainage basins, in: Proc. Symp. Effects of Forest Land Use on Erosion and Slope Stability, East-West Center, University of Hawaii, Honolulu, 99107, 1984.

Sidle, R. C., Pearce, A. J., and O'Loughlin, C. L.: Hillslope Stability and Land Use, Am. Geophys. Union, Washington DC, ISBN 087590-315-0, 19-30, 1985.

Sivapalan, M., Takeuchi, K., Franks, S. W., Gupta, V. K., Karambiri, H., Lakshim, V., Liang, X., McDonnell, J. J., Mendiondo, E. M., O'Connell, P. E., Oki, T., Pomeroy, J. W., Schertzer, D., Uhlenbrook, S., and Zehe, E.: IAHS Decade on predictions in ungauged basins (PUB), 2003-2012: Shaping an exciting future for the hydrological sciences, Hydrol. Sci. J., 48, 857-880, 2003.

Sklash, M. G. and Farvolden, R. N.: The role of groundwater in storm runoff, J. Hydrol., 43, 45-65, 1979.

Soil Conservation Service: National Engineering Handbook, Section 4 Hydrology, US Department of Agriculture, Washington DC, 1972.

Sueishi, T.: On the runoff- analysis by the method of characteristics - Hydraulic studies on the run-off phenomena of rain water 2nd report-, Trans. of JSCE, 29, 74-87, 1955 (in Japanese with English abstract).

Sugawara, M.: Tank model, in: Computer Models in Watershed Hydrology edited by: Singh, V. J., Water Resources Publications, Highland Ranch, 165-214, 1995.

Sugawara, M. and Katsuyama, Y.: On runoff mechanisms in Takaragawa Experimental Watersheds, Science and Technology Agency, Tokyo, 69 pp., 1957 (in Japanese. The title is translated into English by the present author).

Sugiyama, H., Kadoya, M., Nagai, A., and Lansey, K.: Evaluation of the storage function model parameter characteristics, J. Hydrol., 191, 332-348, 1997.

Suzuki, M.: The properties of a baseflow recession on small mountainous watersheds (I) Numerical analysis using saturatedunsaturated flow model, J. Jap. For. Soc., 66, 174-182, 1984 (in Japanese with English abstract).

Takagi, F. and Matsubayashi, U.: On the non-linearity of subsurface and groundwater runoff, Trans. of JSCE, 11, 149-150, 1979.

Takahashi, T.: Mechanical characteristics of debris flow, J. Hydraul. Div., ASCE, 1048, 1153-1169, 1978.

Tani, M.: The properties of a water-table rise produced by a onedimensional, vertical, unsaturated flow, J. Jpn. For. Soc., 64, 409418, 1982 (in Japanese with English abstract).

Tani, M.: Analysis of one-dimensional, vertical, unsaturated flow in consideration of runoff properties of a mountainous watershed, J. Jpn. For. Soc., 67, 449-460, 1985a (in Japanese with English abstract).

Tani, M: The effects of soil physical properties on the groundwatertable rise, Proceedings of the Internat. Symp. Erosion, Debris Flow and Disaster Prevention edited by: Takei A., The Erosion Control Engineering Society, Japan, Tokyo, 361-365, 1985 b.

Tani, M.: Runoff generation processes estimated from hydrological observations on a steep forested hillslope with a thin soil layer, J. Hydrol., 200, 84-109, 1997. 
Tani, M.: Analysis of runoff-storage relationships to evaluate the runoff-buffering potential of a sloping permeable domain, J. Hydrol., 360, 132-146, doi:10.1016/j.jhydrol.2008.07.023, 2008.

Tani, M. and Abe, T.: Analysis of stormflow and its source area expansion through a simple kinematic wave equation, Forest Hydroloy and Watershed Management, IAHS Publ. No. 167, 609615, 1987.

Tani, M. and Hosoda, I.: Dependence of annual evapotranspiration on a long natural growth of forest and vegetation changes, J. Japan Soc. Hydrol. Water Resour., 25, 71-88, 2012 (in Japanese with English abstract).

Tani, M., Fujimoto, M., Katsuyama, M., Kojima, N., Hosoda, I., Kosugi, K., Kosugi, Y., and Nakamura, S.: Predicting the dependences of rainfall-runoff responses on human forest disturbances with soil loss based on the runoff mechanisms in granitic and sedimentary-rock mountains, Hydrol. Process., 26, 809-826, doi:10.1002/hyp.8295, 2012.

Troch, P. A., Paniconi, C., and Loon, E. E.: Hillslopestorage Boussinesq model for subsurface flow and variable source areas along complex hillslopes: 2. Formulation and characteristic response, Water Resour. Res., 39, 1316, doi:10.1029/2002WR001728, 2003.

Tromp-van Meerveld, H. J. and McDonnell, J. J.: Threshold relations in subsurface stormflow: 1. A 147-storm analysis of the Panola hillslope, Water Resour Res., 42, W02410, doi:10.1029/2004WR003778, 2006.

Tsukamoto, Y.: Study on the growth of stream channel I - relationship between stream channel growth and landslides occurring during heavy storm, J. Japan Soc. Erosion Control Engineering, 87, 4-13, 1973 (In Japanese).
Tsukamoto, Y. and Ohta, T.: Runoff process on a steep forested slope, J. Hydrol., 102, 165-178, 1988.

Tsukamoto, Y., Ohta, T., and Noguchi, H.: Hydrological and geomorphological studies of debris slides on forested hillslopes in Japan, in: Recent developments in the explanation and prediction of erosion and sediment yield, IAHS Publ. 137, 89-98, 1982.

Uchida, T., McDonnell, J. J., and Asano, Y.: Functional intercomparison of hillslopes and small catchments by examining water source, flowpath and mean residence time, J. Hydrol., 327, 627642, doi:10.1016/j.jhydrol.2006.02.037, 2006.

Verma, R. D. and Brutsaert, W.: Unconfined aquifer seepage by capillary flow theory J. Hydraul. Div., ASCE, 96, 1331-1344, 1970.

Wang, J. S. Y. and Narashimhan, T. N.: Hydrologic mechanisms governing fluid flow in a partially saturated, fractured, porous medium, Water Resour. Res., 21, 1861-1874, 1985.

Weiler, M. and McDonnell, J. J.: Conceptualizing lateral preferential flow and flow networks and simulating the effects on gauged and ungauged catchments, Water Resour. Res., 43, W03403, doi:10.1029/2006WR004867, 2007.

Weiler, M., McDonnell, J. J., Tromp-van Meerveld, I., and Uchida, T.: 112 Subsurface stormflow, in: Encyclopedia of Hydrological Sciences, edited by: Anderson, M. G., John Wiley \& Sons, Hoboken, doi:10.1002/0470848944.hsa119, 2006.

Yamakawa, Y., Kosugi, K., Masaoka, N., Tada, Y., and Mizuyama, T.: Use of combined penetrometer-moisture probe together with geophysical methods to survey hydrological properties of a natural slope, Vadose Zone J., 9, 768-779, doi:10.2136/vzj2010.0012, 2010. 